Journal of Educational

and Psychological Sciences

Volume (5), Issue (29) : 30 Aug 2021

P: 164 - 184

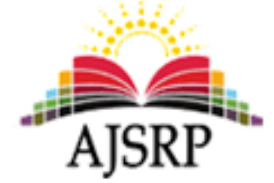

ISSN: 2522- 3399

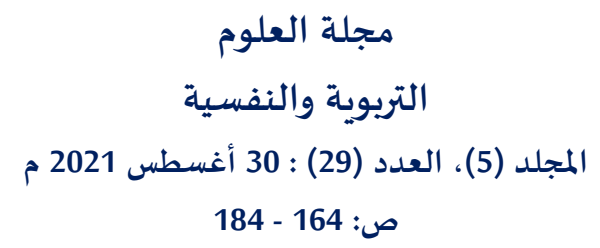

ص: 164 - 184

\title{
The ability to predict personality factors with a tendency to violence and its relationship to family security for a sample of the Kasbah of the capital,
}

\author{
Amman \\ Ishraq Yousef AL- Tarawneh \\ Ishraqat Center for Scientific Consulting || Jordan \\ Noor Elayyan Al- Manaseer \\ Nuseibah Mohammad Banitaha \\ Ministry of Education || UAE
}

\begin{abstract}
The present study aimed to reveal the extent to which personality factors predict the tendency towards violence and its relationship to family security, and the study adopted the predictive, relational, descriptive approach. The study sample consisted of (422) fathers aged between (55-30) years from Al Mazar area in Karak Governorate, Jordan. To achieve the objectives of the study, the personality factors scale was used, the development of two scales (tendency towards violence and family security), and indicators of honesty and consistency were found and applied to the study individuals. A percentage (0.267) of the explained variance of the tendency towards violence and that the factor of openness to experience and alertness of conscience explained in its society a percentage (0.189) of the variance explained by family secure, The researcher presented a set of recommendations, including the necessity of conducting educational awareness programs for parents with methods of correct dealing and socialization, managing violence, developing counseling programs for parents in particular and families in general focusing on awareness of the characteristics of personality factors and their impact on family stability, holding workshops and organizing awareness campaigns for communities. The Arabic language in general, and the Jordanian in particular, and the definition of the impact of violence and its threat to family security and stability.
\end{abstract}

Keywords: Personal factors, The tendency to violence, family security.

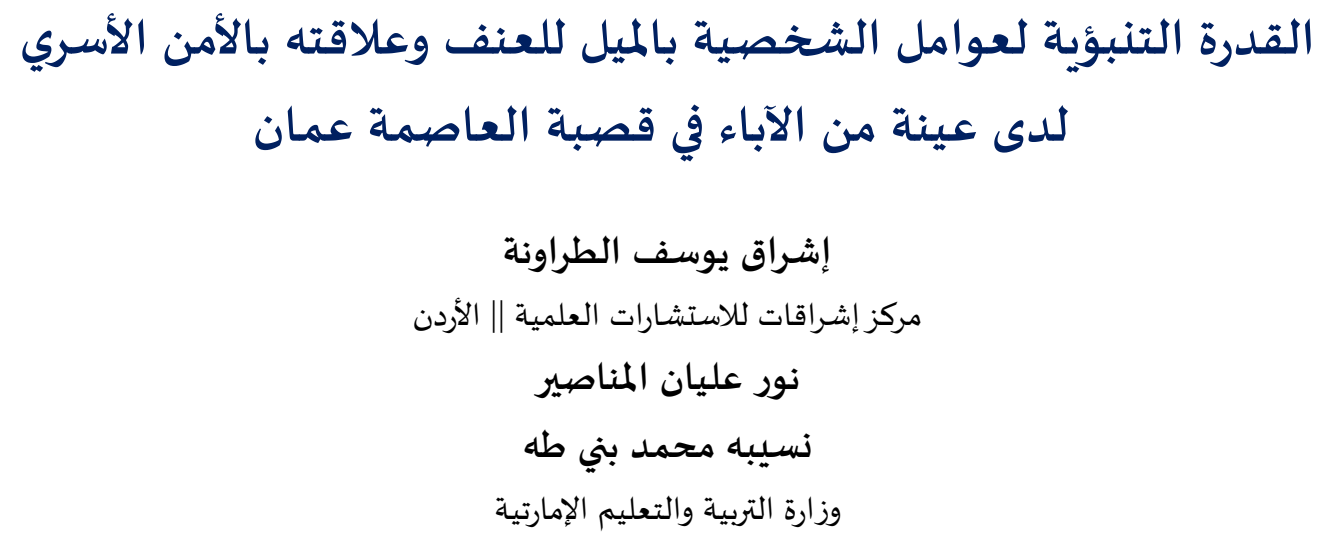




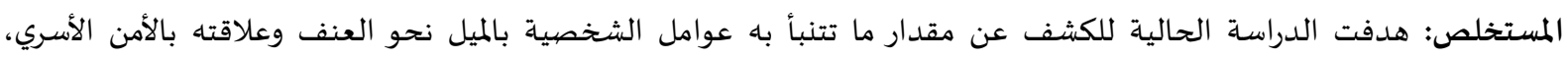

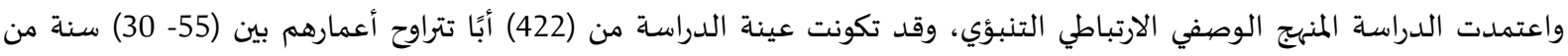

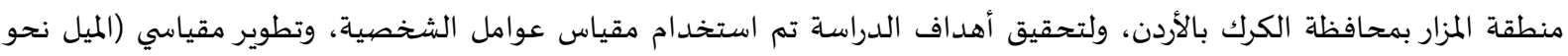

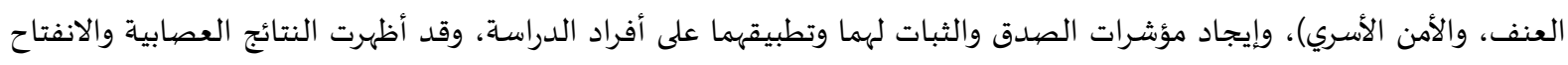

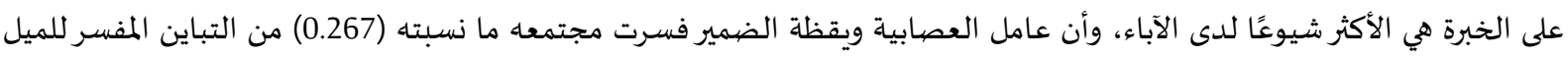

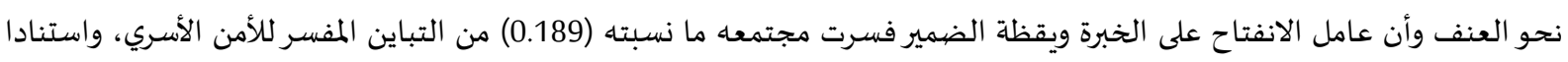

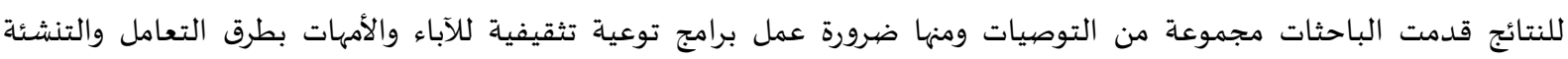

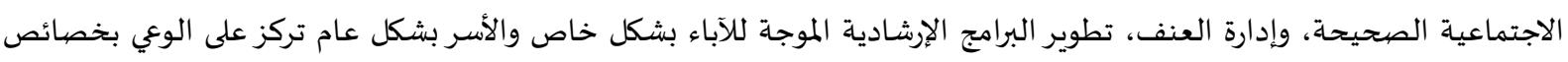

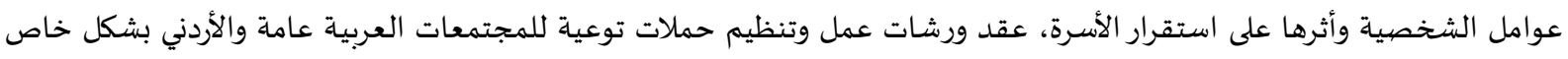
والتعريف بأثر العنف وتهديده للأمن الأسري واستقراره.

الكلمات المفتاحية: عوامل الشخصية، الميل للعنف، الأمن الأسري.

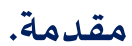

يعد الآباء أولى الشخصيات المهمة في حياة الطفل، والعماد الأساسي للأسرة الصحية السليمة، ويبرز الدور

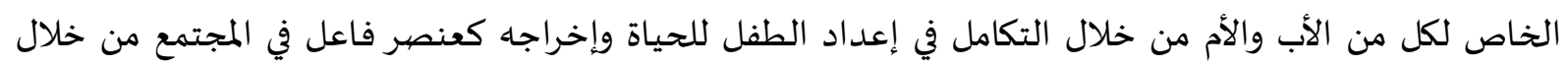

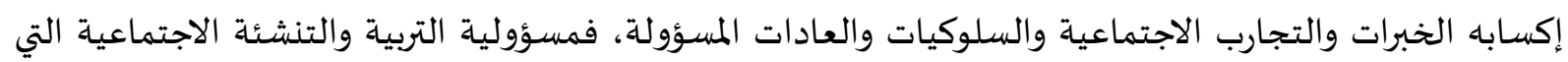

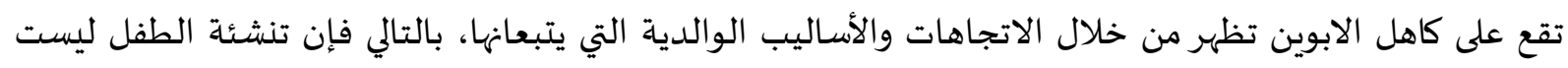

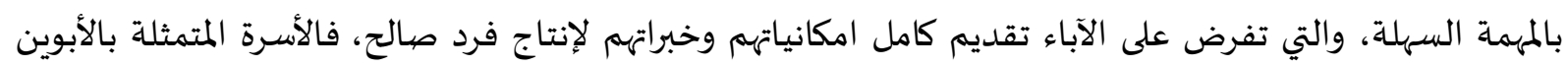

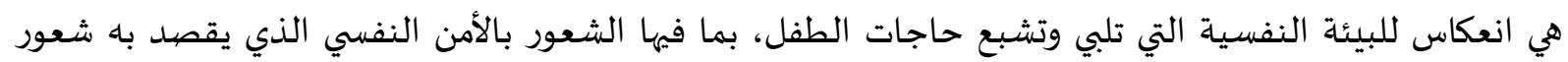

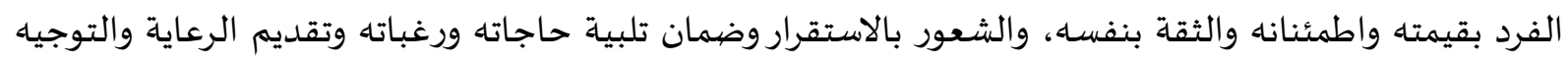

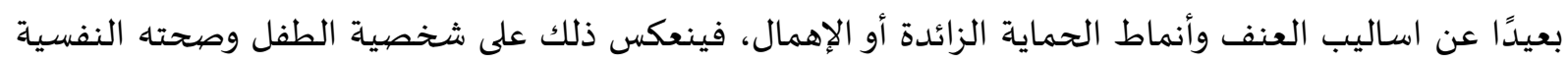

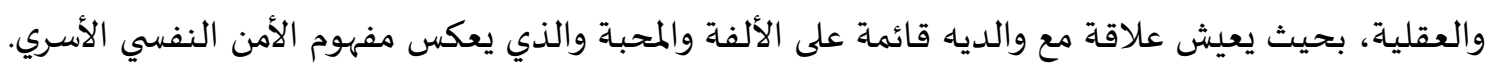

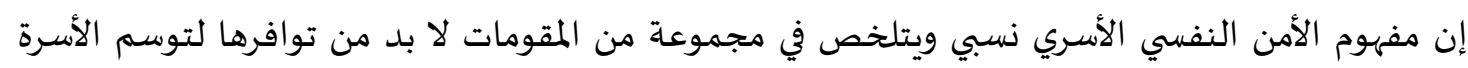

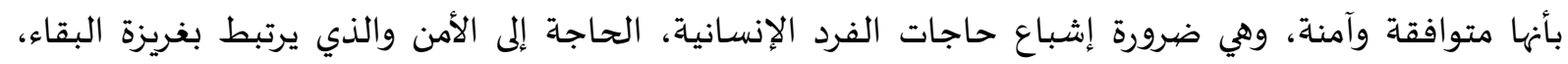

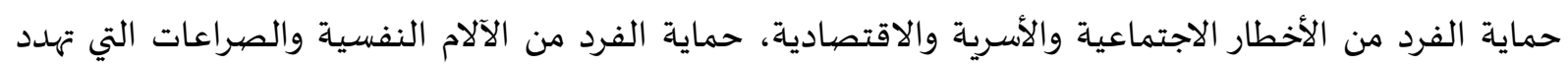

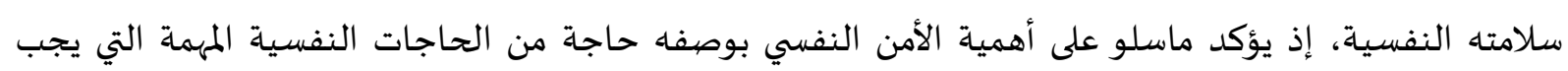

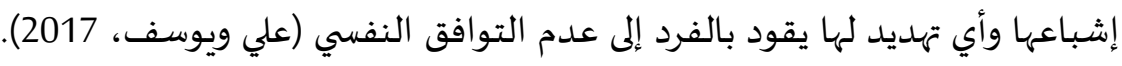

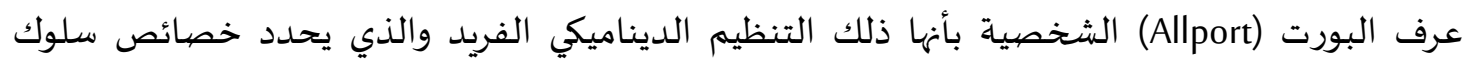
وتفكير الفرد، وقد اهتم علماء النفس بمفهوم عوامل الشخصية حيث قاموا بترتيها كفئات وتنظيمها على شكل الثربل

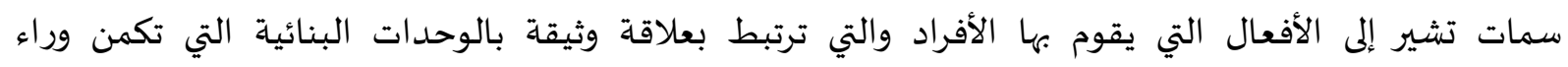
الشخصية، فقد نشر ألبورت (Allport) دراسة عام 1936 تضمنت قائمة بـ (18000) سمة إنسانية، ثم قام كاتل

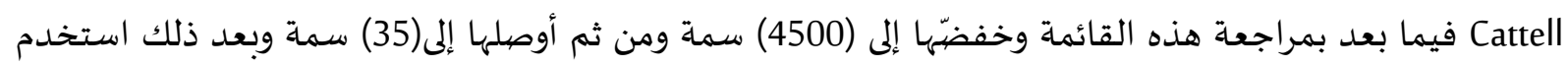
التحليل العاملي لهذه السمات واستخراج (16) عاملاً للشخصية، ثم قام كل من كوستا وماكري (Costa \&McCrae) بتخفيض هذه القائمة لتضم خمسة عوامل للشخصية سُميت بعد ذلك بالعوامل الخمسة الكبرى في الشمات الشخصية وهي العصابية والانبساطية والطيبة ويقظة الضميروالانفتاح على الخبرة(Costa \&McCrae, 1985). 
يعد الشعور بالأمن النفسي من المطالب الأساسية لجميع الأشخاص في كل فئات المجتمع باختلاف

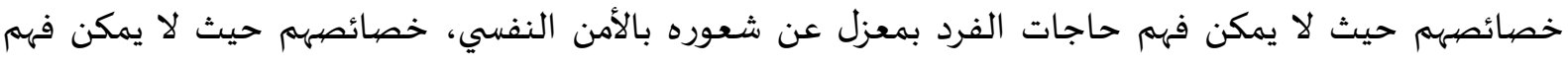

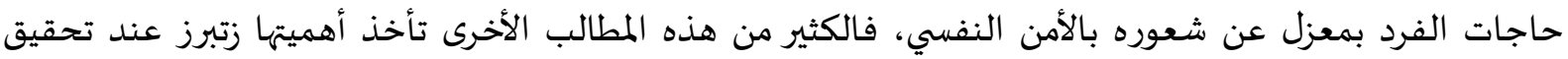

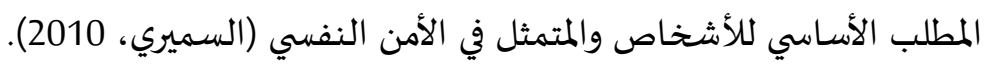

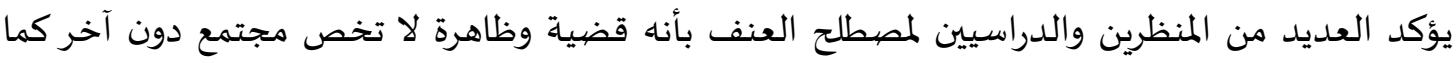

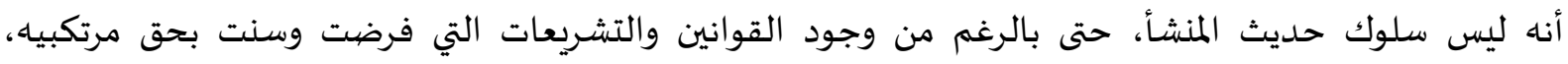

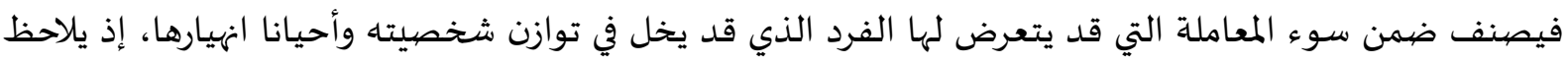

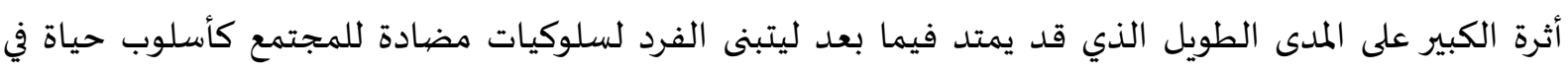

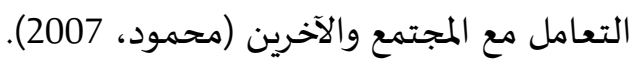
قدم العديد من الباحثين تفسيرات متعددة للسلوك العنيف، فيرى دولارد (Dollard) أن الإحباط مولد أساسي للسلوك العنيف فعرقلة مسيرة الفرد في تحقيق هدف ما في سبيل تلبية حاجاته تخلق لدية مشاعر الإحباط العباط

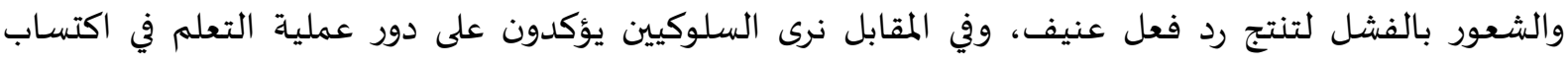

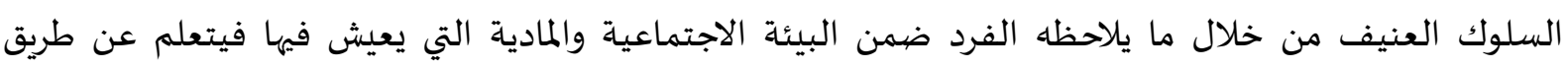

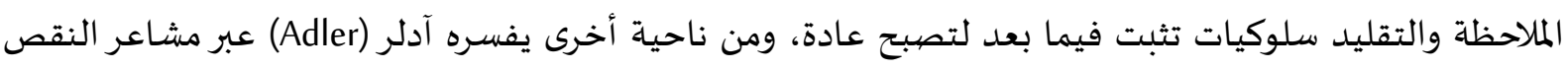

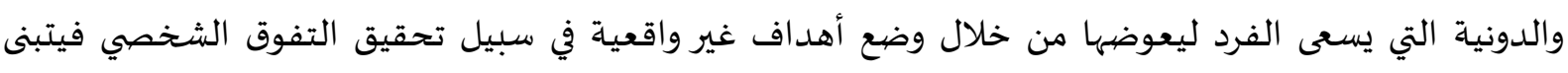

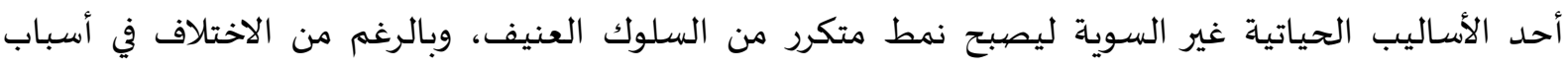

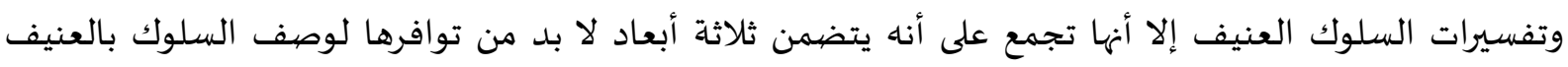

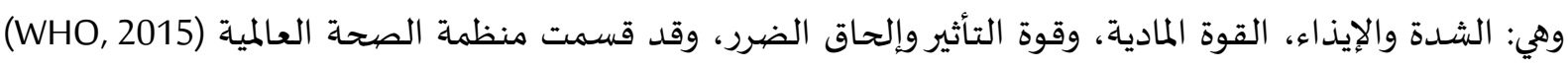

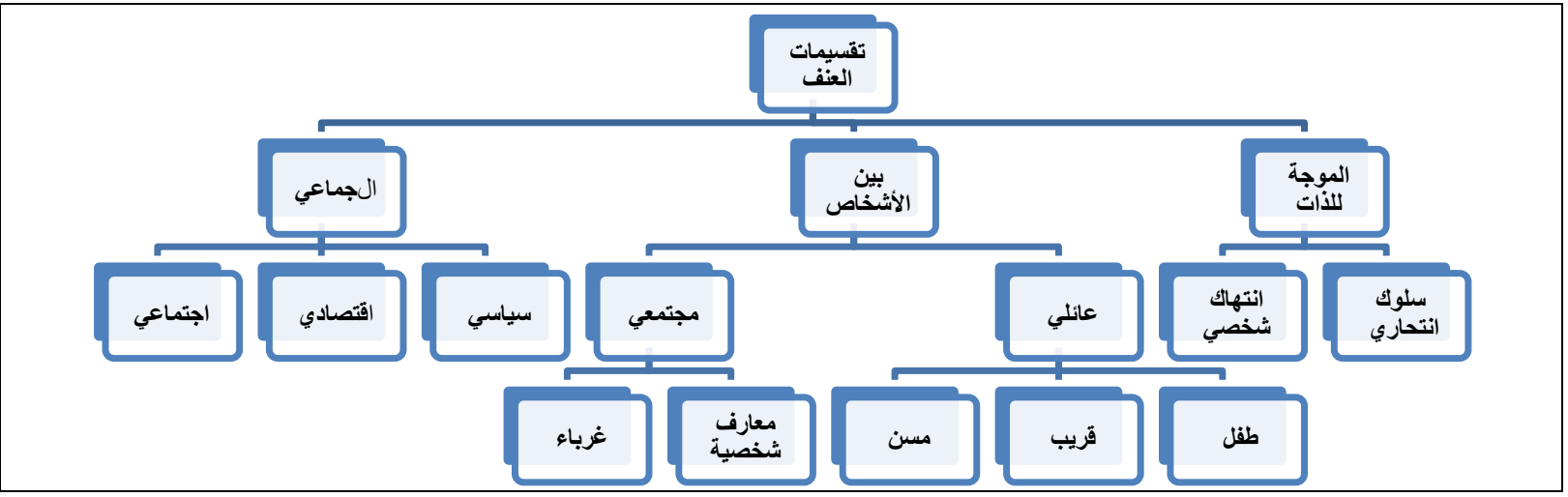

الشكل (1) تقسيمات العنف حسب منظمة الصحة العالمية (WHO, 2015)

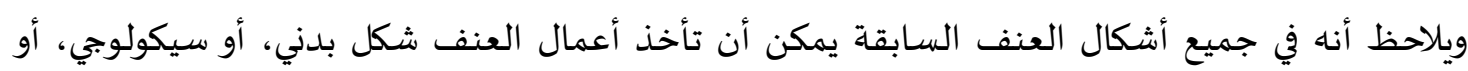
جنسي، أو حرمان وإهمال.

وقد أشارت المنظمة إلى تقسيمات متعددة لأسباب ودوافع العنف منها: أسباب ذاتية ترجع إلى شخصية

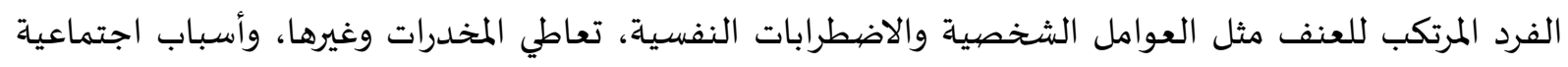

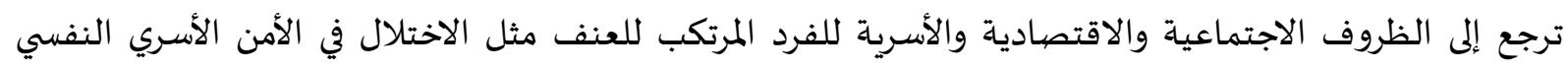

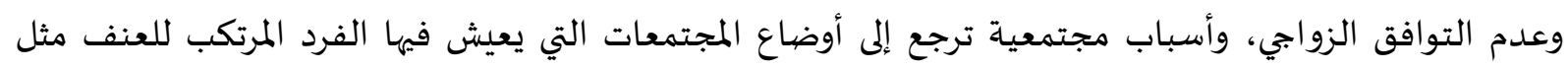
الحروب، الخلافات العشائرية والتعصب. واسبات مجنئ. 
مشكلة الدراسة وأسئلتها:

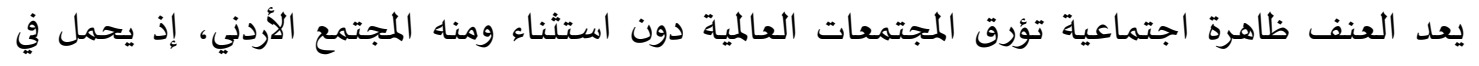

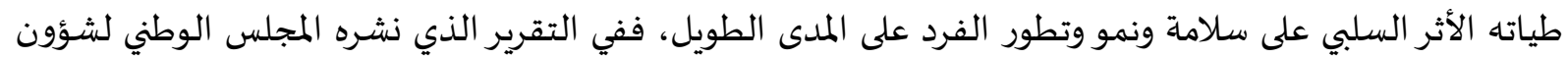

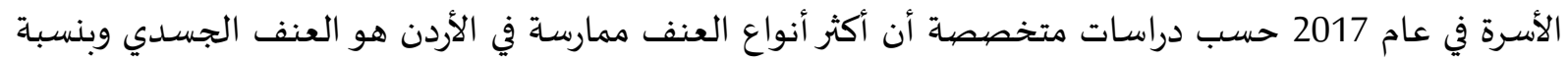

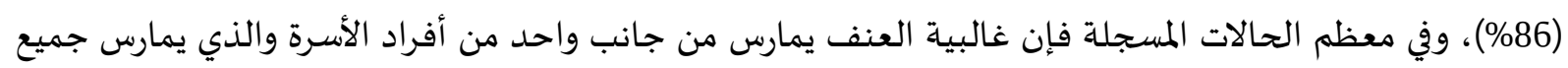

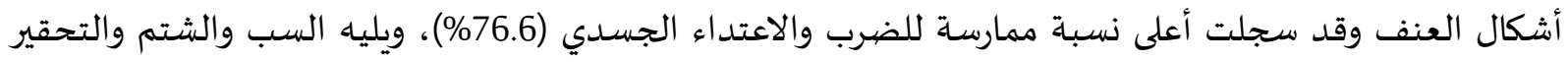
(51.4\%)، والصراخ (20.3\%)، والحرمان الاقتصادي (18.5\%)، وأخيرًا الإهمال (18.1\%) الذئل الذي يعطي مؤشر خطير على سلامة الأمن النفسي الأسري والمجتمعي على السواء.

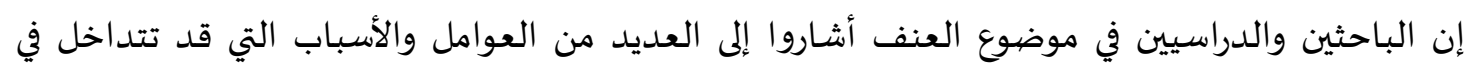

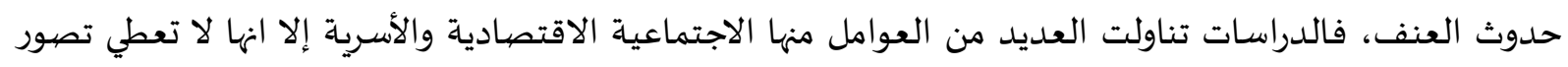

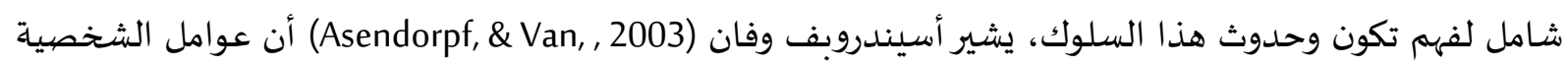

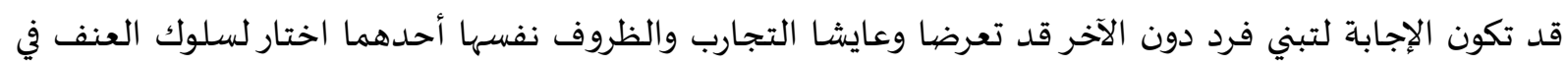

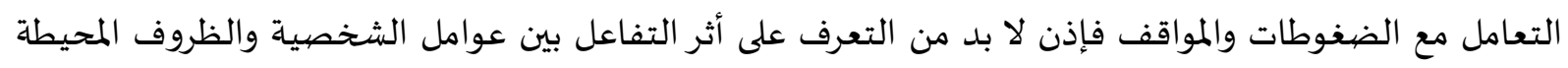

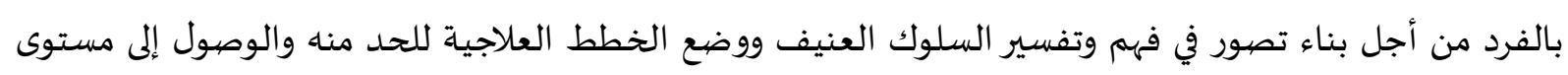
مناسب من الأمن النفسي الأسري والمجتمعي.

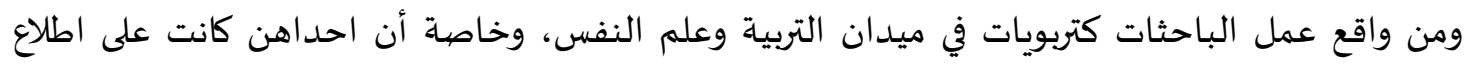

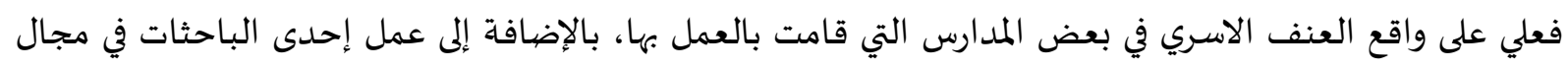

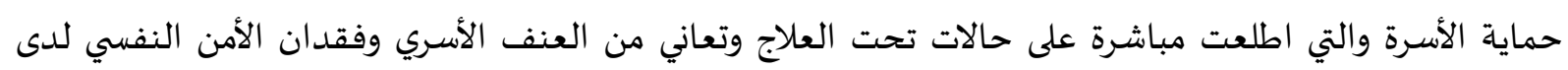

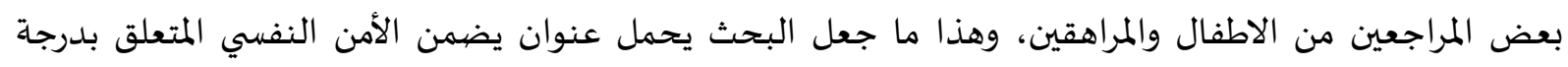

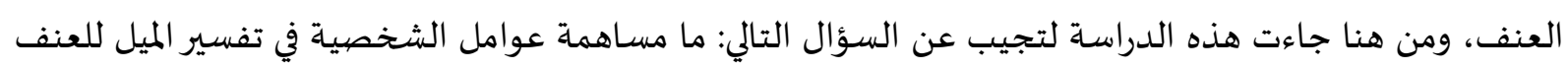
وعلاقته بالأمن الأسري لدى الآداء؟ هده الداء

أسئلة الدراسة

1- - ما عوامل الشخصية الأبرز لدى عينة الدراسة؟ الدراسه

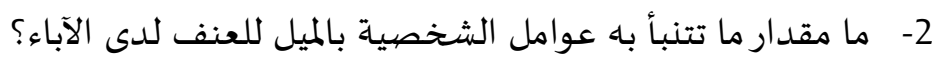

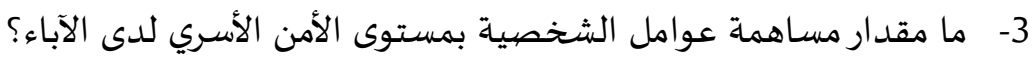

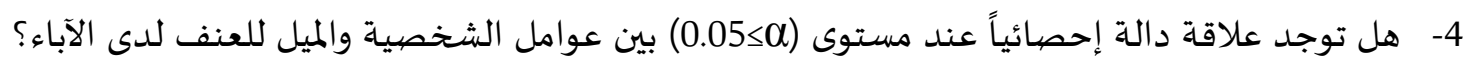
5- هل هنالك علاقة دالة إحصائياً عند مستوى (م>0.05) بين الميل للعنف والأمن الأسري لدى الآباء؟

أهداف الدراسة

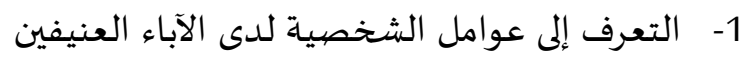
2- التعرف على مساهمة عوامل الشخصية في تفسير الميل للعنف وتحقيق الأمن النفسي الأسري لدى الآباء. 
تعود أهمية الدراسة الحالية إلى أهمية الموضوع الذي تتناوله، وهو تسليط الضوء على موضوع الآباء ودورهم في تحقيق الأمن النفسي، ومعرفة مساهمة عوامل الشخصية في تفسير الميل للعنف لديهم، بالتالي تساعد الداء على رسم صورة واضحة لتكونه وتفسيره، وتتحدد أهمية الدراسة في الجانبين التاليين:

الأهمية النظرية 1- - تقدم هذه الدراسة معرفة نظرية تتعلق بعوامل الشخصية الشائعة لدى الآباء العنيفين، وهذه المعرفة قد تساهم في فهم الميل للعنف لديهم. 2- تعتبر الدراسـة الحالية إضافة للمعرفة العلمية الخاصة بالدراسات التي تناولت تفسير حدوث العنف وهذه المعرفة قد تسهم في فهمه وتفسيره، وإلقاء الضيوء عليه كسبب في عدم تحقيق الأمن النفسي الأسري.

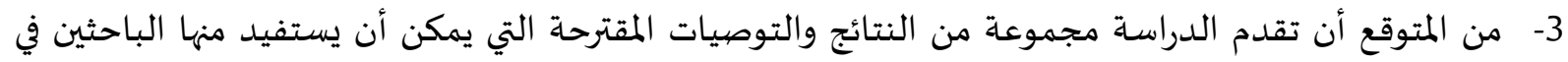
مجال الأسرة والوالدين.

الأهمية التطبيقية 1- تساهم الدراسة الحالية في تقديم فهم شامل لمفهوم عوامل الشخصية وأثرها في الميل للسلوك العنيف وتحقيق

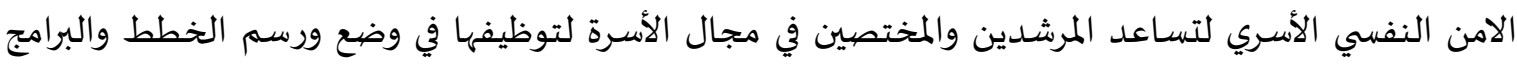

$$
\text { العلاجية. }
$$

2- تلقي الدراسة الحالية الضوء على جانب مهم في شخصية الآباء وهي عوامل الشخصية وكيف تؤثر على الصحاة النفسية للفرد، وهذا أمر مهم من أجل فهم ديناميكيات السلوك البه مهن العنيف.

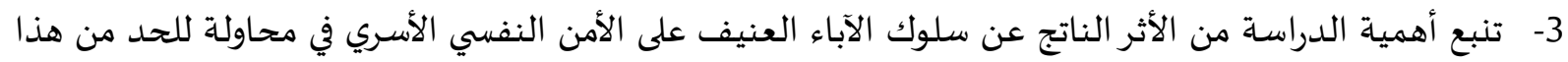
الأثر.

حدود الدراسـة تتحدد الدراساة الحالية بما يلي: المحددات الموضوعية: تحدد نتائج الدراسة بدقة إجابة أفراد الدراسة على المقاييس المستخدمة.

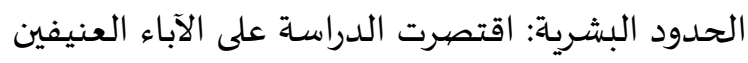

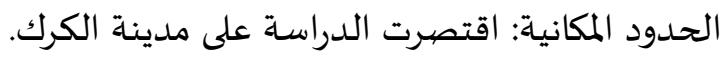
الحدود الزمنية: تم تطبيق الدراسة الحالية خلال شهري كانون الثاني وشباط من العبات العرب 2018.

التعريفات الإجرائية والمفاهيمية

Personality Factors O عرف وولمان (Wolman) المذكور في (الربيع، 2007) عوامل الشخصية: بأها تلك التأثيرات الكامنة والمسئولة عن

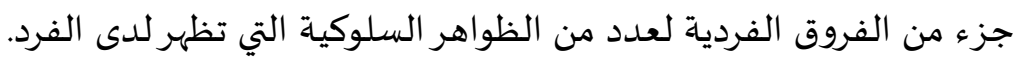

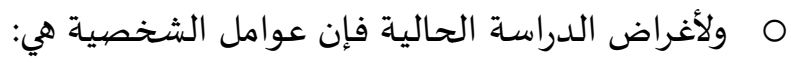


- العصابية (Neuroticism): ويتميز أصحاب هذا النمط بالسمات الانفعالية السلوكية السلبية مثل القلق

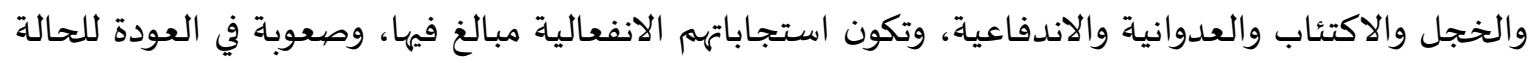

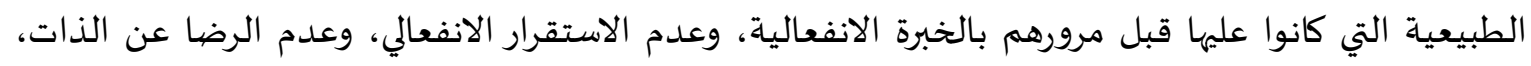
وصعوبة في التكيف مع متطلبات الحياة، وعدم الثقة بالنفس، وعدم القدرة على مساعدة الآخرين.

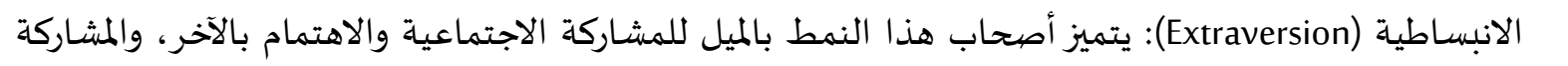
في حل المشكلات بشكل ايجابي، ويميلون إلى الحيوية والنشاط والبحثث عن الإثارة، ويتميزون بالحزم والتفاؤل ودفء المشاعر. يقظة الضمير(Conscientiousness): يتميز أصحاب هذا النمط بالكفاءة، والتنظيم، والثبات، والمسؤولية،

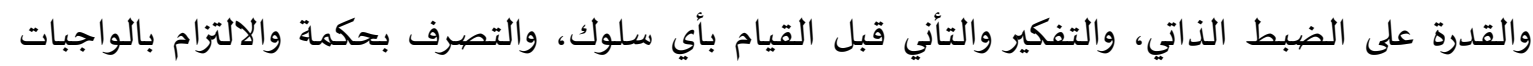

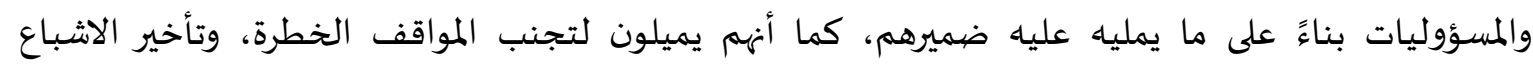
والدافعية المرتفعة. المقبولية (الطيبة) Agreeableness: ويتميز أصحاب هذا النمط بالكفاءة الذاتية، والثقة بالنفس، والاهتمام

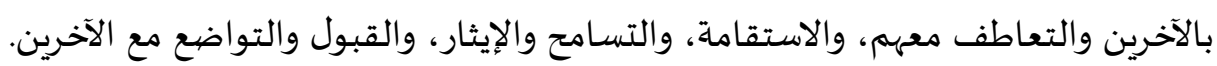

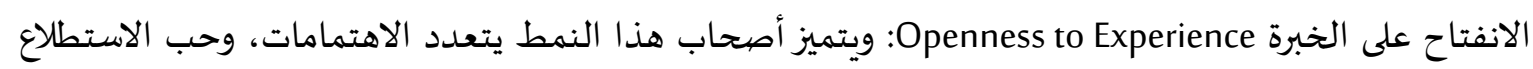

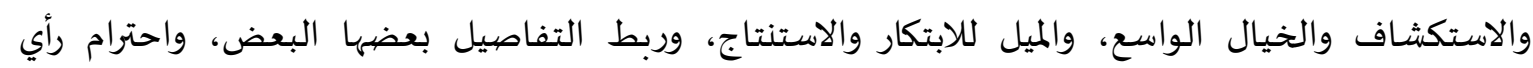

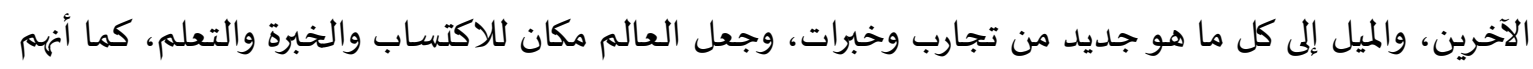

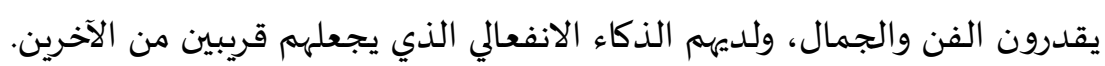

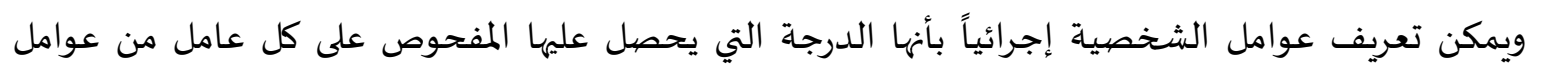
الشخصية في المقياس المعد لأغراض الدراسة الحالية.

-

عرفت منظمة الصحة العالمية (WHO) العنف في تقريرها الأول الخاص بالصحة والعنف بأنه " الاستخدام

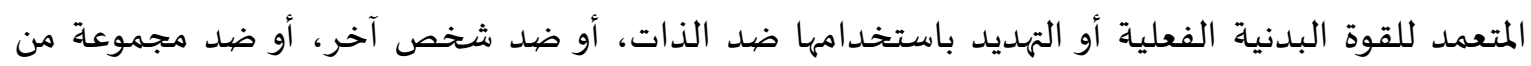

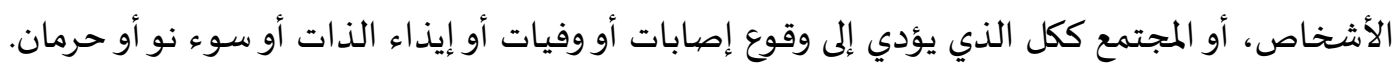

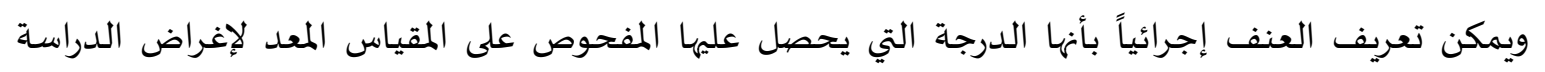
الحالية.

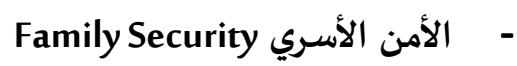
ه يعرفه الحسني (2016) بأن الأمن الشامل والسلامة في جميع جوانب الحياة الأسرية النفسية، والمعيشية،

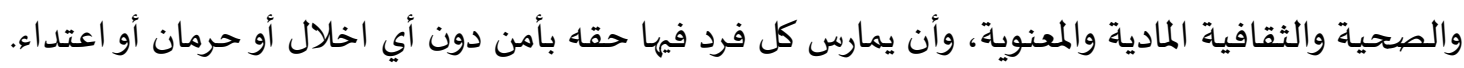

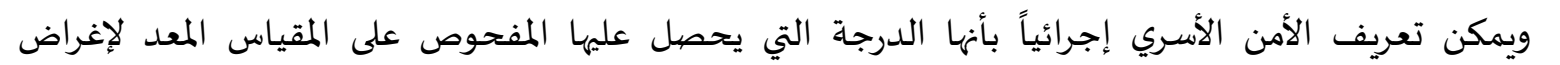
الدراسة الحالية.

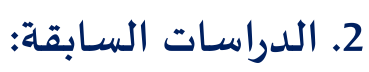
إن الدراسـات التي تناولت عوامل الشخصية والعنف والأمن الأسري معًا قليلة، وسيتم التعرف إلى الدراسـات 
- أجرى موتيفاليان وآخرون (Motevaliyan, et al, . 2017) بدراسة هدفت التعرف على عوامل الشخصية

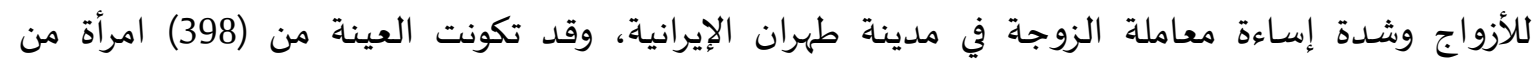

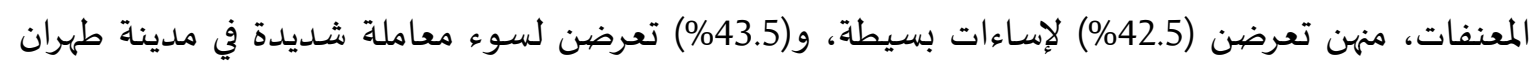

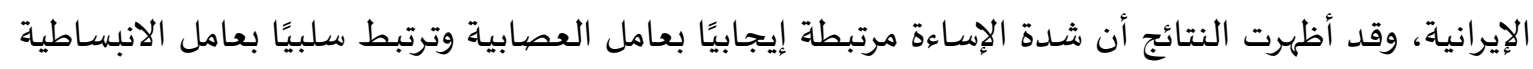

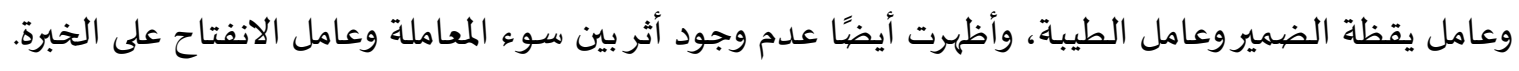
كما وأجرى الطيار (2013) دراسة هدفت التعرف على العلاقة التفاعلية في التنشئة الاجتماعية بين الآباء

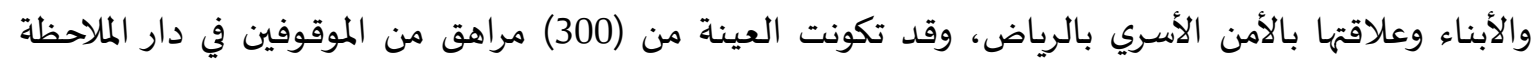

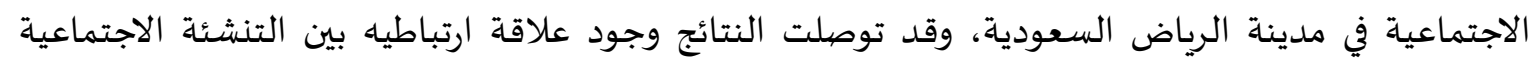

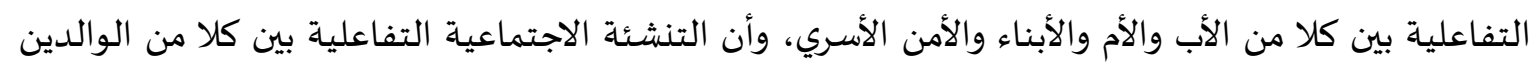

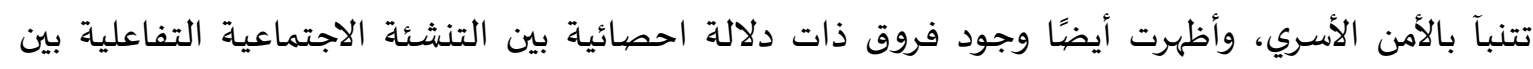

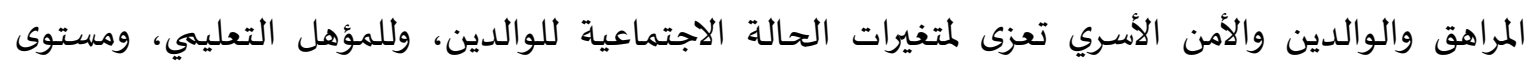

الدخل.

وأجرى السويطي (2012) دراسة هدفت التعرف العلاقة بين العنف الأسري نحو الأبناء بالشعور بالأمن لدى

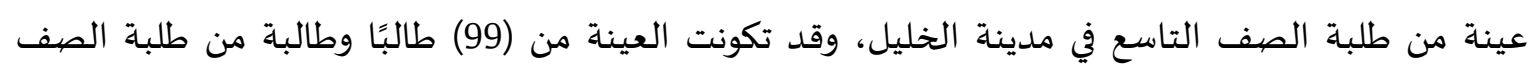

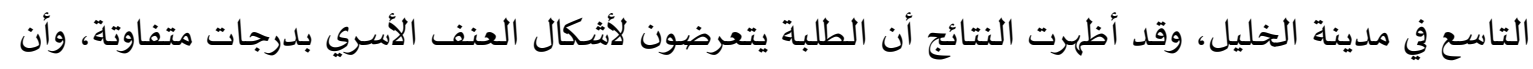

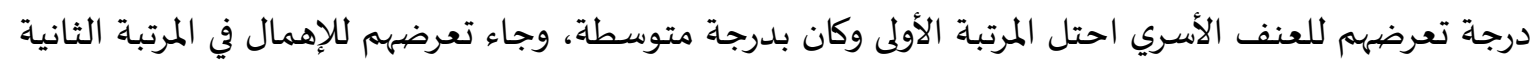

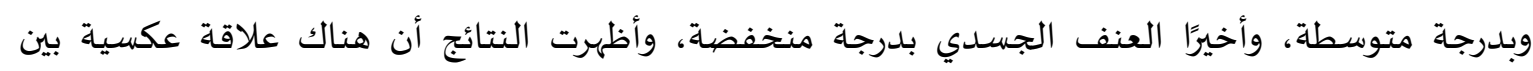

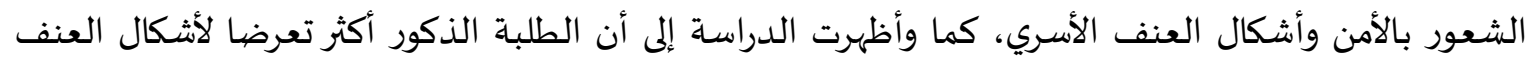
الأسري من الإناث.

أجرى أبريعم (2011) دراسة هدفت التعرف على أساليب معاملة الأب وعلاقته بالشعور بالأمن النفسي لدى

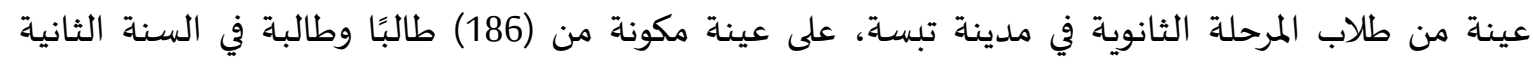

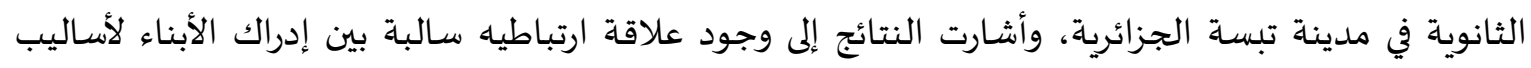

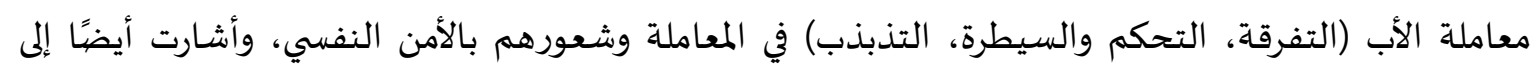

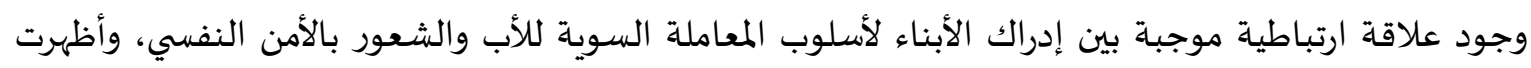

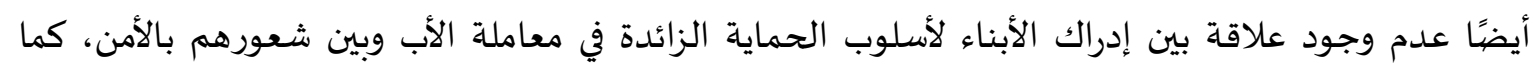

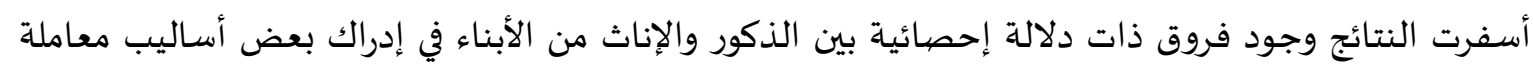
الأب، وعدم وجودها في إدراك أساليب المعاملة الأخرى. أجرت باريس وآخرون (Bares, et al., 2011) دراسة هدفت فهم الشخصية الأبوية والعوامل الأسرية المساهمة

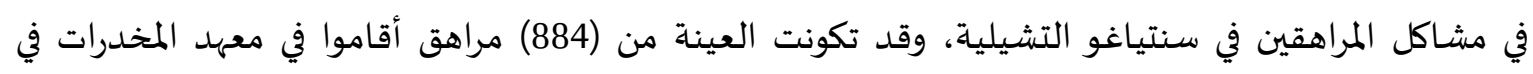

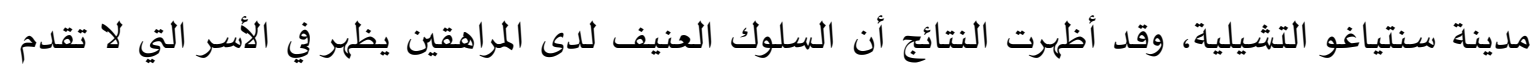

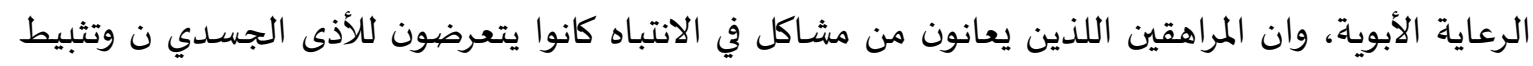
سلوكهم، وعدمم اهتمام الوالدين. في دراسة قام بها برينز وآخرون (Prinzie, et al, 2009) هدفت التعرف على العلاقة بين عوامل الشخصية الخمسة الكبرى وثلاثة من أبعاد الأبوة (الدفء، التحكم السلوكي، دعم الاستقلالية) في مدينة امستردام

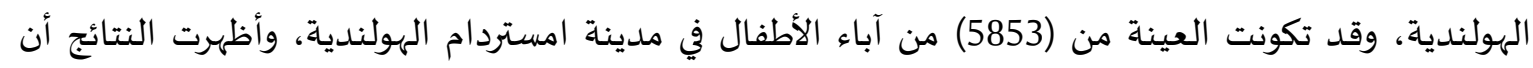


عامل الانبساطية وعامل الانفتاحية وعامل يقظة الضمير ترتبط إيجابيًا ببعدي الدفء والتحكم السلوكي

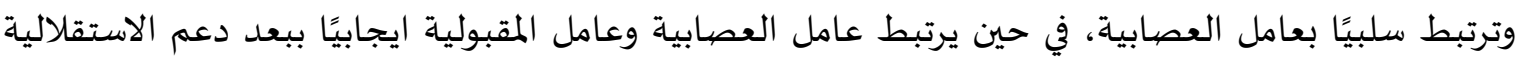

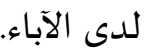

كما وقدم الفراية (2006) بدراسة هدفت التعرف على العنف الأسري الموجة نحو الأبناء وعلاقته بالشعور

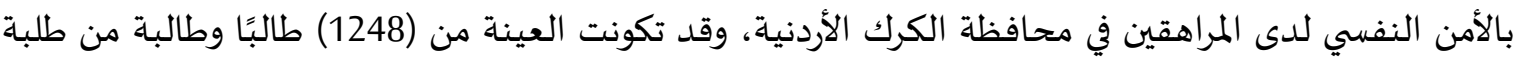

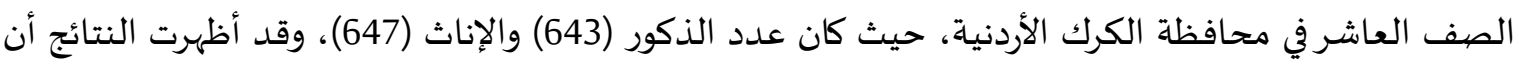

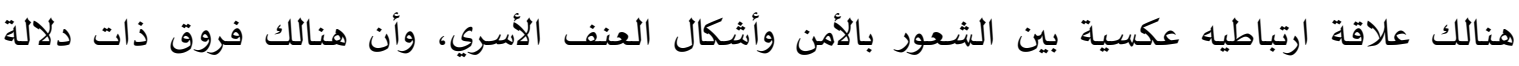

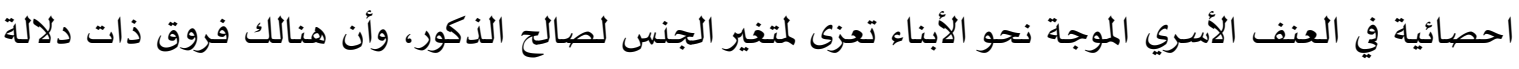

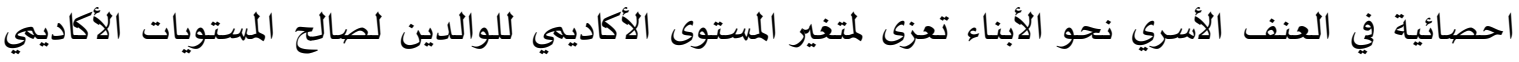
المتدني. وقدم شـاهونج وإيفا (Shanhong \& Eva, 2005)بدراسة تهدف إلى التعرف على مدى تأثير التجانس بين

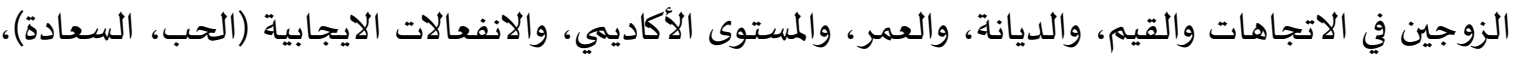

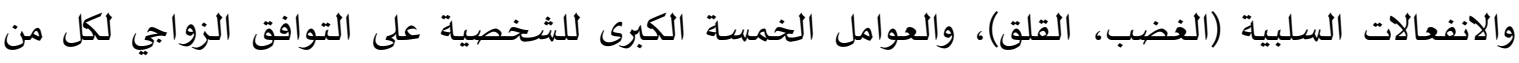

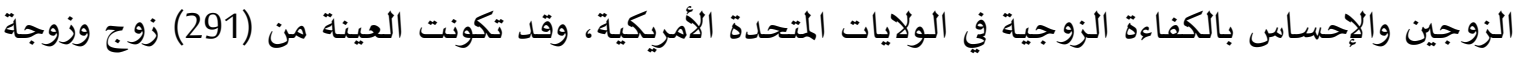

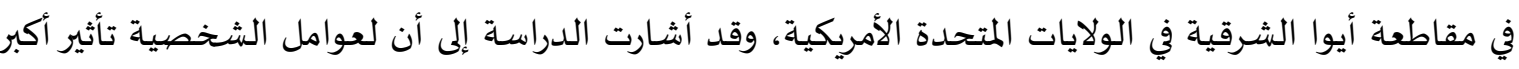

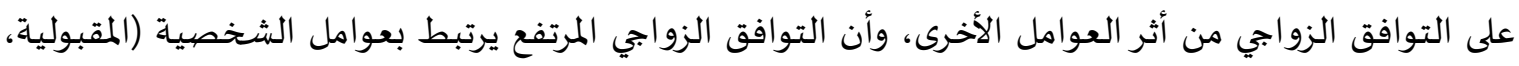

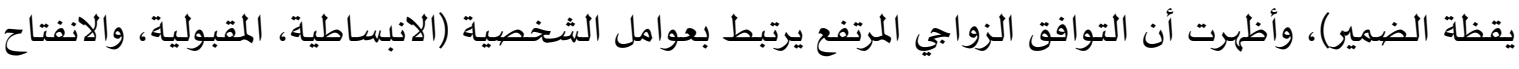

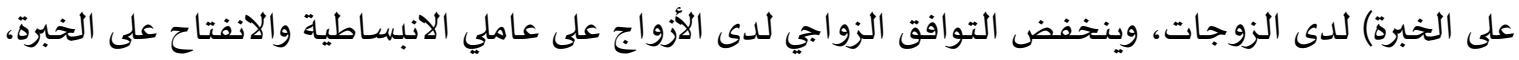

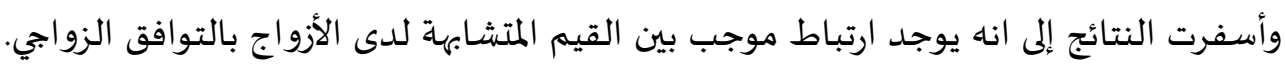
وفي دراسة قام بها دايفس وفورمان (Davies \& Forman, 2004) هدفت التعرف على دور الأمن النفسي

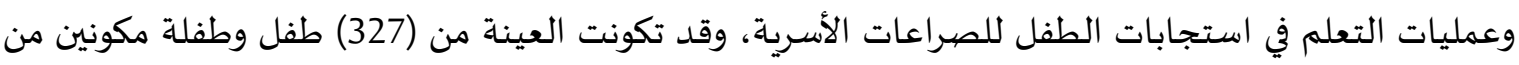

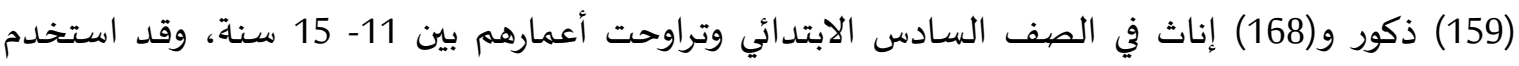

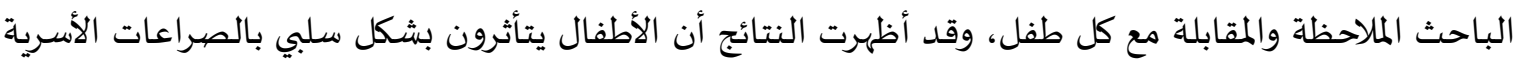

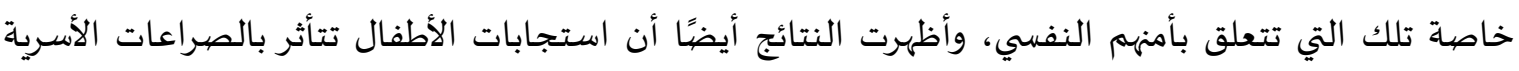

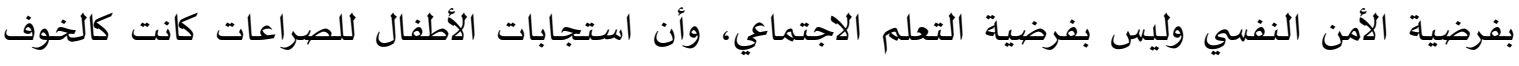

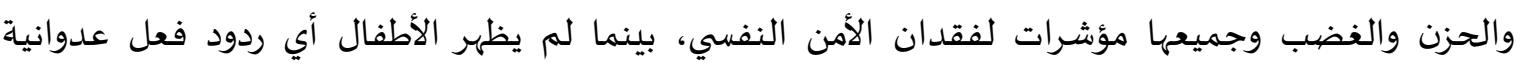
كاستجابة للصراعات الأسرية حسي فرضية وأسية التعلم الاجتماعي.

التعقيب على الدراسات السابقة: يلاحظ أن الدراسات العربية والأجنبية التي تناولت موضيوع عوامل الشخصية بالميل للعنف وعلاقته بالأمن

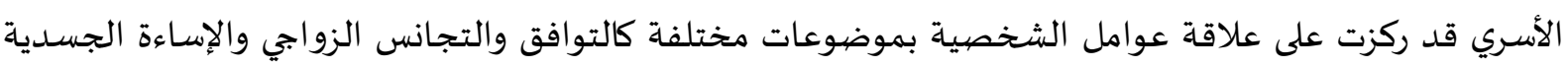

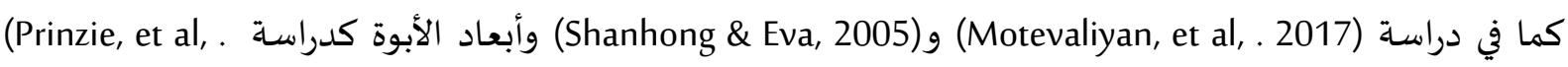

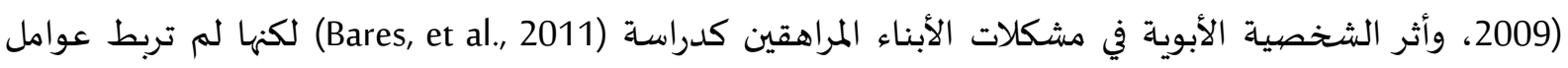

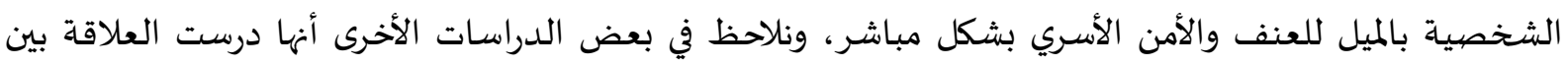

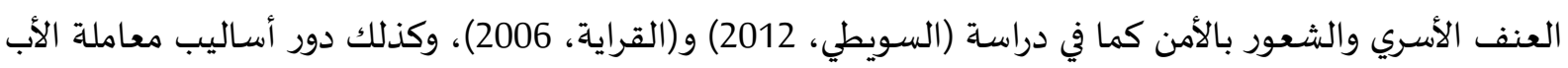


وعلاقته بالشعور بالأمن النفسي في دراسة (أبريعم، 2011)، ودور التنشئة الاجتماعية التفاعلية بالتنبؤ بالأمن

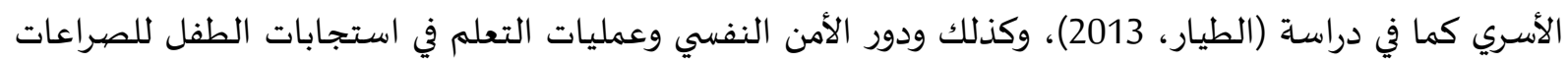
الأسرية في دراسة (Davies \& Forman, 2004) دون ربطها بعوامل الشخصية، وإذ يتضح ندرة الدراسات التي أشارت

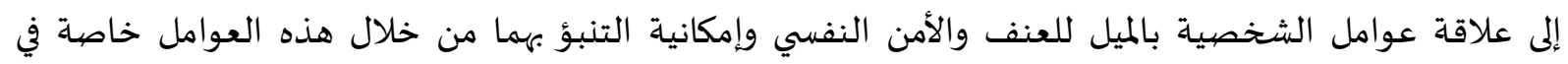

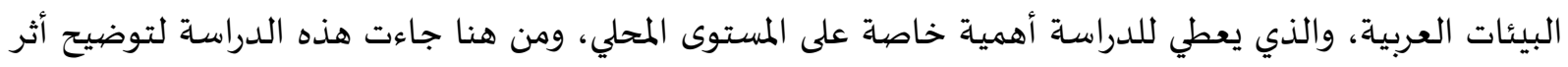

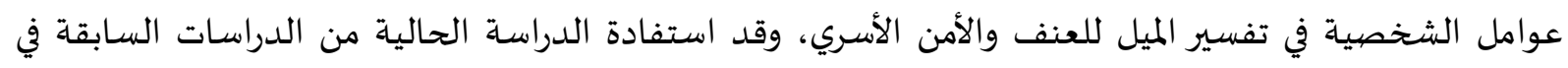
استخدام وبناء المقاييس وفي طريقة المعالجة.

الطريقة والإجراءات

تعتمد الدراسة على المنهج الوصفي الارتباطي التنبؤي الذي يقوم على ايجاد علاقة بين متغيرين أو أكثر

وكذلك التنبؤ بالظاهرة من خلال متغيرات أو عوامل متعددة.

مجتمع الدراسة وعينتها تكونت عينة الدراسة الحالية من الآباء المقيمين في منطقة المزار في محافظة الكرك الأردنية والبالغ عددهم

(422) والجدول (1) يبين خصائص العينة بناءً على الجنس والفئة العمرياة: الجدول رقم (1) وصف خصيائص العينة العينة

\begin{tabular}{|c|c|c|}
\hline العدد & فئات المتخير & المتغير \\
\hline 211 & ذكور (الآباء) & \multirow{3}{*}{ الجنس } \\
\hline 211 & اناث (الأمهات) & \\
\hline 422 & الكلي & \\
\hline 116 & 20 - 29 سنة & \multirow{4}{*}{ الفئة العمري } \\
\hline 172 & 30 - 39 سنة & \\
\hline 134 & 40 فاكثر & \\
\hline 422 & الكلي & \\
\hline
\end{tabular}

$$
\text { أدوات الدراسة }
$$

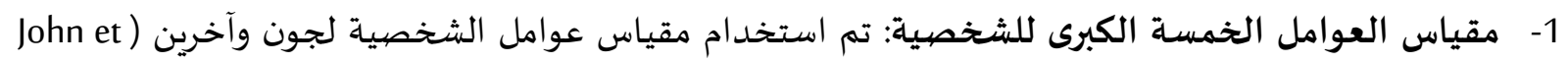
(al., 191

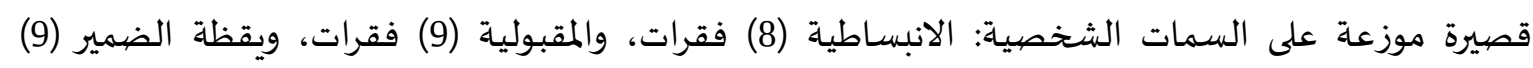

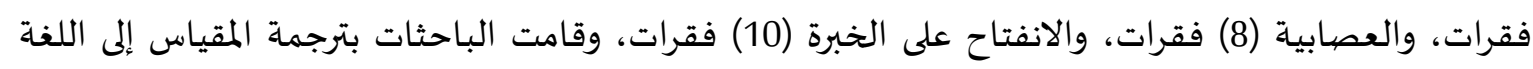

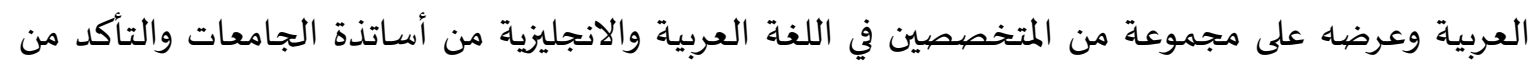

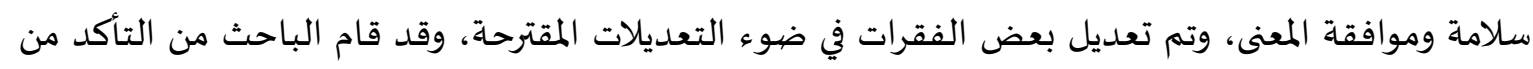
صدق وثبات المقياس الذي استخدمت في المقياس الأصلي لجون وآخرين (John et al., 191) بالطرق التوات التالية: 
صبدق المقياس:

- - الصدق الظاهري: تم عرض الأداة على (7) من المحكمين من أعضاء الهيئة التدريسية في الجامعات الأردنية من

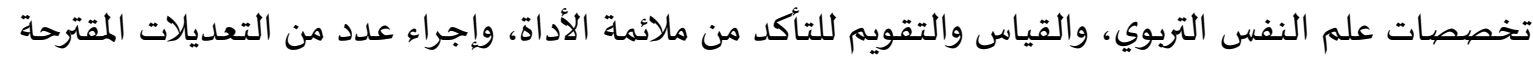

على بعض الفقرات، وبذلك بقي المقياس كما هو مكونًا من (44) فقرة دون حذف ونس أي منها. صدق البناء: تم تطبيق الأداة على عينة استطلاعية مكونة من (29) معلم ومعلمة من خارج عينة الدراسة، وحساب معاملات الارتباط بين كل فقرة والدرجة الكلية للبعد الذي تنتهي إلية باستخدام معامل ارتباط بيرسون، وقد تراوحت معاملات ارتباط كل فقرة مع كل بعد من أبعاد الشخصية الذي تنتمي إلية كما يلي: الانبساطية (0.30- 0.53)، والطيبة (0.28- 0.65)، ويقظة الضمير (0.31- 0.70)، والعصابية (0.29- 0.68)،

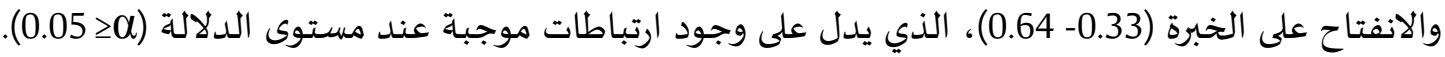

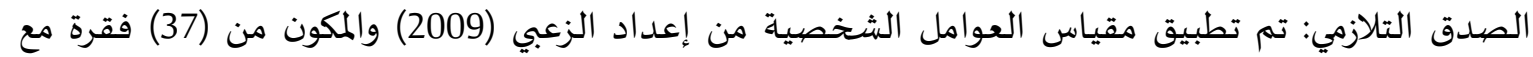
مقياس عوامل الشخصية المستخدم في الدراسة الحالية من أجل حساب الصددق التلازمي بين درجات كل عامل من عوامل الشخصية الخمسة الكبرى بين المقياسين، وتم حساب الارتباط بين كل عامل من عوامل الشخصية

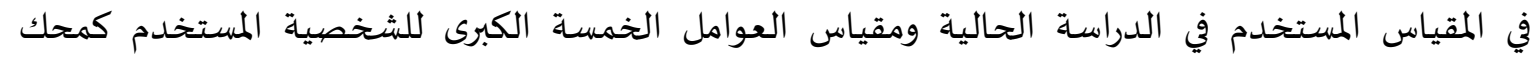
وأظهرت النتائج أن: الانبساطية (0.88)، والمقبولية (0.84)، ويقظة الضيمير (0.77) والعصابية (0.89)، والانفتاح

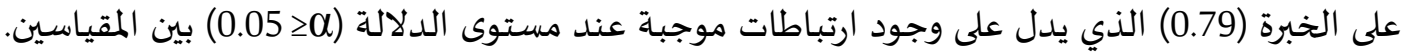

ثبات المقياس: - الإعادة وإعادة التطبيق: تم حساب معامل الثبات للمقياس بطريقة الإعادة من خلال تطبيقه على عينة مكونة من (29) معلمًا ومعلمة بفارق أسبوعين بين التطبيق الأول والثاني: وأظهرت النتائج أن معاملات الارتباط كانت كالتالي: الإنبساطية (0.83)، المقبولية (0.76)، ويقظة الضمير (0.86)، والعصبابية (0.89)، الانفتاح على الخبرة

الاتساق الداخلي: تم حساب معامل الثبات من خلال حساب معامل كرومباخ ألفا (Cronbach's Alpha) على

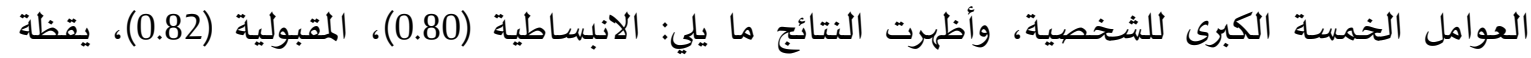
الضمير (0.81)، العصابية (0.87)، الانفتاح على الخبرة (0.78).

طريقة التصحيح

للإجابة على المقياس تم استخدام تدريج "ليكرت" الخماسي (أوافق بشدة، أوافق، متردد، أعارض، أعارض بشدة) بحيث تعطى التدريجات الدرجات (5، 4، 3، 2، 1) على الترتيب في حالة الفقرات الايجابية، والعكس في الفقرات السلبية، ولتحديد مستويات استجابات المفحوصين على المقياس، فقد تم تصنيف المتوسطات الحسابية على مستوى الفقرة الواحدة أو أي عامل من عوامل الشخصية وفق المعيار التالي: (2.49 فأقل) مستوى منخفض،

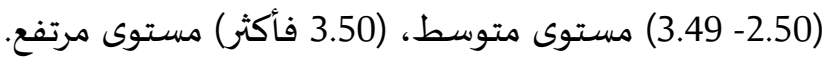

2- مقياس الميل للعنف: طور مقياس الميل للعنف في الدراسة الحالية من خلال الرجوع إلى الأدب السابق المتعلق

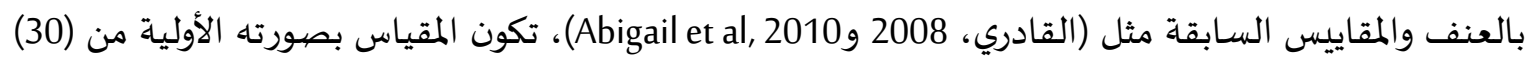

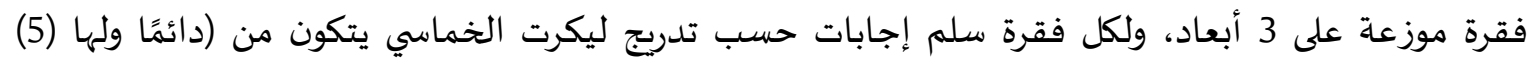


درجات، عادة ولها (4) درجات، وأحيانًا ولها (3) درجات، نادرًا ولها (2) درجة، أبدًا ولها (1) درجة، وللمقياس

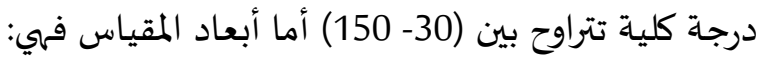

البعد الأول: العنف التنفيذي: ويتكون هذا البعد من (10) فقرات وتصف البت استجابات الفرد العنيفة مثل

(الكراهية، اللوم، التآمروالابتزاز).

البعد الثاني: العنف البدني: ويتكون هذا البعد من (10) فقرات وتصف التبتجاباتات الفرد العنيفة مثل

$$
\text { (الضرب، الاشتباك بالأيدي، الصفع والصعق). }
$$

البعد الثالث: العنف اللفظي: ويتكون هذا المقياس من (10) فقرات وتصف استجاباتات الفرد العنيفة مثل

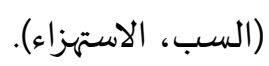

صبدق المقياس

للتحقق من هذا المقياس تم اعتماد المؤشرات التالية:

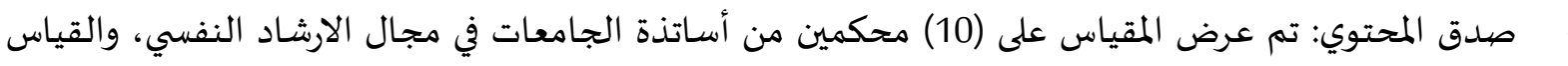

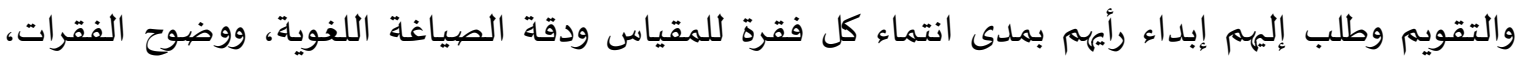

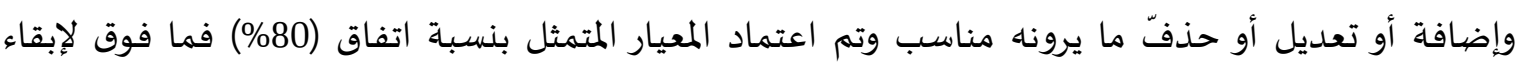

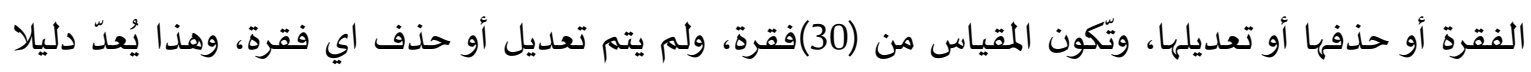
على صدق المقياس. صداق البناء (الاتساق الداخلي: تم إيجاد مؤشرات صداق البناء لمقياس الميل للعنف وذلك بتطبيقه على (30) من الآباء من مجتمع الدراسة ومن خارج عينتها، وتم حساب معاملات ارتباط كل فقرة من فقرات المات المقياس

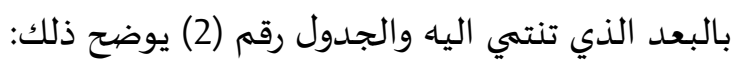

الجدول (2) معامل ارتباط كل فقرة من فقرات مقياس الميل للعنف مع البعد البد الذي تندرج تحته الفقرة

\begin{tabular}{|c|c|c|c|c|c|}
\hline \multicolumn{2}{|c|}{ العنف اللفظي } & \multicolumn{2}{|c|}{ العنف البدني } & \multicolumn{2}{|c|}{ العنف التنفيذي } \\
\hline معامل الارتباط & رقم الفقرة & معامل الارتباط & رقم الفقرة & معامل الارتباط & رقم الفقرة \\
\hline $0.60^{*}$ & 21 & $0.71 *$ & 11 & $0.71 *$ & 1 \\
\hline $0.80^{*}$ & 22 & $0.68^{*}$ & 12 & $*_{0.61}$ & 2 \\
\hline$*^{*} 0.66$ & 23 & $*^{*} 0.70$ & 13 & $0.73^{*}$ & 3 \\
\hline $0.55^{*}$ & 24 & $*^{*} 0.72$ & 14 & $*_{0.51}$ & 4 \\
\hline$*_{0.49}$ & 25 & $0.69 *$ & 15 & $0.69 *$ & 5 \\
\hline $0.51^{*}$ & 26 & $* 0.38$ & 16 & $0.61 *$ & 6 \\
\hline $0.47^{*}$ & 27 & $* 0.72$ & 17 & $* 0.37$ & 7 \\
\hline$* 0.37$ & 28 & $0.87^{*}$ & 18 & $*_{0.48}$ & 8 \\
\hline$* 0.70$ & 29 & $0.65^{*}$ & 19 & $0.82^{*}$ & 9 \\
\hline $0.73^{*}$ & 30 & $*_{0} 0.37$ & 20 & $0.80^{*}$ & 10 \\
\hline
\end{tabular}

*ات دلالة إحصائية عند مستوى دلالة (2)0.05)

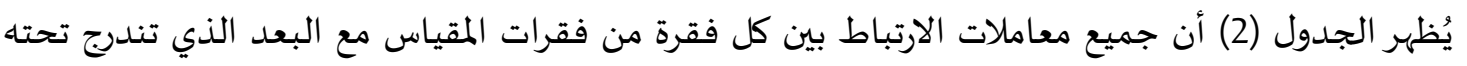

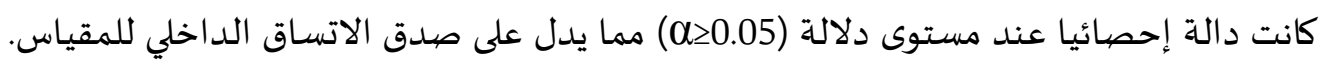


ثبات مقياس الميل للعنف

للتحقق من ثبات مقياس الميل للعنف تم تطبيق المقياس على (30) من الآباء من مجتمع الدراسة ومن

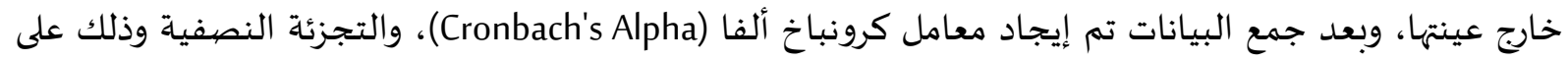

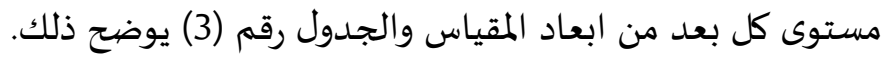
جدول رقم (3): معاملات ثبات مقياس الميل للعنف

\begin{tabular}{|c|c|c|c|}
\hline التجزئة النصفية & كرونباخ الفا & البعد & رقم البعد \\
\hline 20.9 & 0.90 & العنف التنفيذي & .1 \\
\hline 70.8 & 0.84 & العنف البدني & .2 \\
\hline 30.8 & 0.85 & العنف اللفظي & .3 \\
\hline
\end{tabular}

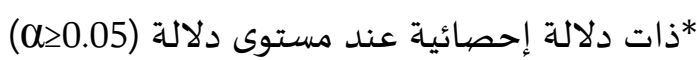

تُظهِ النتائج في الجدول (3) أن معاملات ثبات مقياس الميل للعنف بطريقة كرونباخ المبات ألفا قد تراوحت

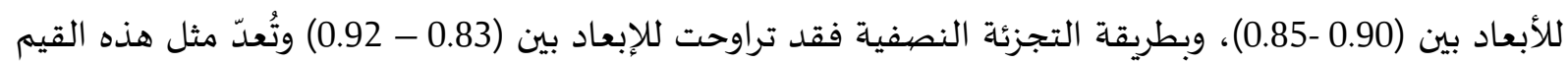
مقبولة لأغراض الدراسة الحالية.

3- مقياس الأمن الأسري: طور مقياس الأمن الأسري في الدراسة الحالية من خلال الرجوع إلى الأدب السابق

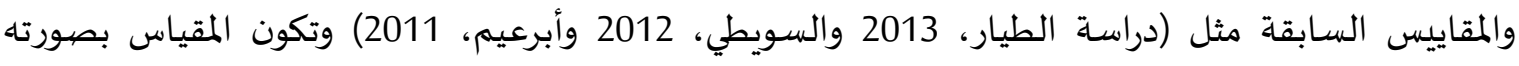

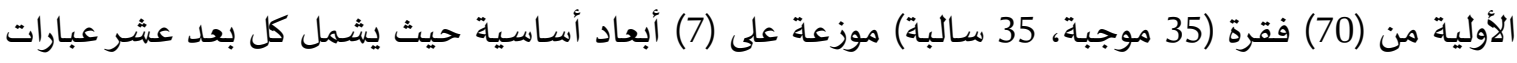

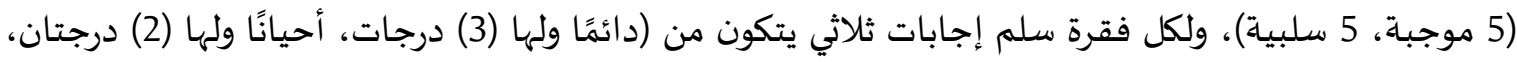
نادرًا ولها (1) درجة)، في حال كانت الفقرة ايجابية ويُعكس سلم الدرجات والتقديرات للفقرات السلبات السلبية

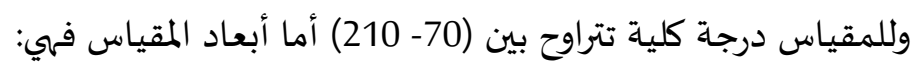
البعد الأول: قدرة الأسرة على مواجهة مشكلاتها، ويقيس مدى قدرات قدرة الفرد في الأسرة هلى مناقشّة مشكلاته،

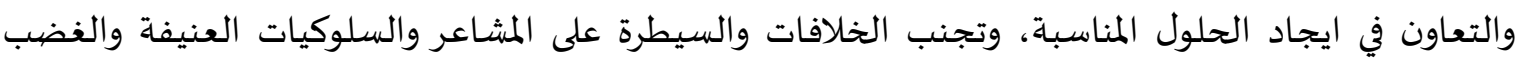

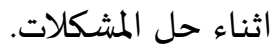
البعد الثاني: الاستقرار الأسري، ويقيس مدى الاستقرار والتفاهم والشعور بالراحة والأمان لدى أفراد الأسرة وقدرتهم على التكيف مع الضغوطات والظروف الجديدة الطارئة. البعد الثالث: التماسك الأسري، ويقيس مدى الانتماء والترابط والتعاون بين أفراد الأسرة واهتمامهم ومساعدنهمه

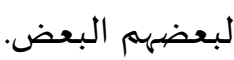

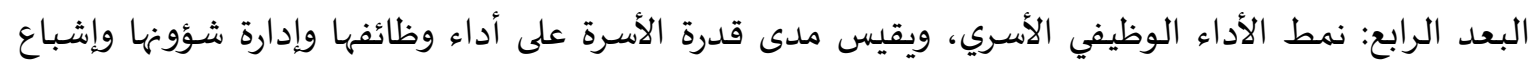

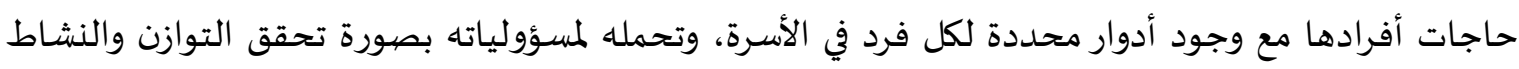
والحيوية للأسرة. البعد الخامس: نمط العلاقات الأسرياة، ويقيس مدى العلاقات القوية في تفاعلات أفراد الأسرة جميعًا، وبين

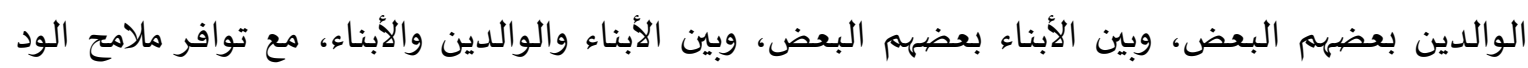
والتوافق ووضوح العلاقات. البعد السادس: الشعور بالرضا والسعادة لدى أفراد الأسرة، ويقيس الشعور بالسعادة والرضيا والتفاؤل لدى أفراد الأسرة، والبعد عن المشكلات والقلق وتجنب ما يخلق الخلافات والحزن بين أفرادها. 
- البعد السابع: تجنب الصراعات الأسرية، ويقيس قدرة الأسرة على تجنب الصراع وضبط الغضب، والانفعالات الشديدة لدى أفراد الأسرة.

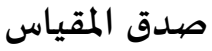
- - صدق المحتوى: لأغراض الدراسة الحالية تم عرض المقياس على (10) محكمين من أساتذة الجامعات في مجال

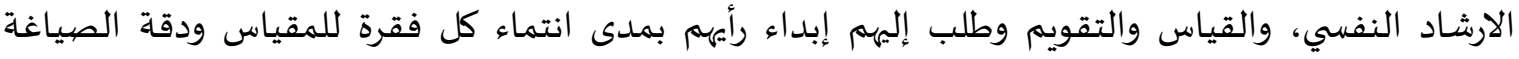

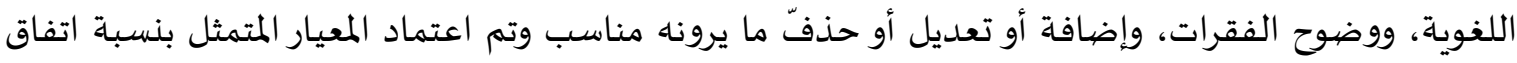

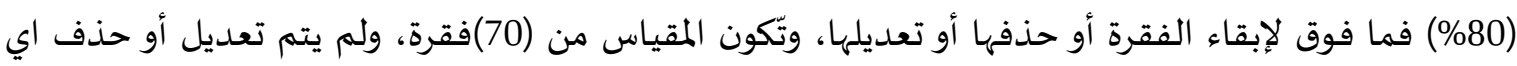

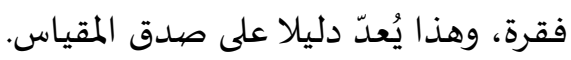

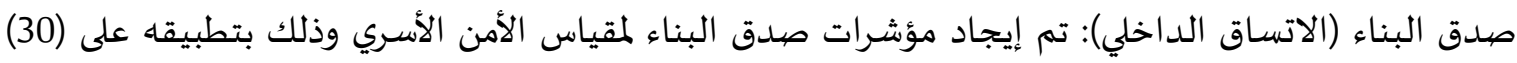

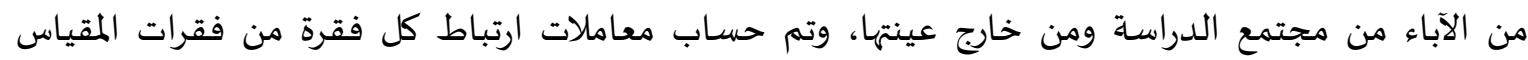

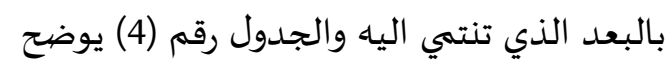

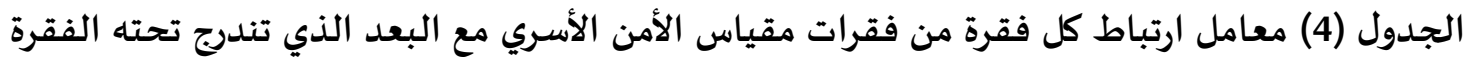

\begin{tabular}{|c|c|c|c|c|c|c|c|c|c|c|c|}
\hline معامل الإرتباط & العامل & الفقرة & معامل الإرتباط & العامل & الفقرة & مع الإرتباط & العامل & الفقرة & معامل الإرتباط & العامل & الفقرة \\
\hline${ }^{*} 0.62$ & \multirow{10}{*}{ الهبراع } & 61 & $0.27^{*}$ & \multirow{10}{*}{ الأسراية } & 41 & $0.38^{*}$ & \multirow{10}{*}{ الأسمري } & 21 & $0.80^{*}$ & \multirow{10}{*}{ المشلى حل } & 1 \\
\hline${ }^{*} 0.66$ & & 62 & $0.53^{*}$ & & 42 & $0.20^{*}$ & & 22 & $0.44^{*}$ & & 2 \\
\hline$*_{0.47}$ & & 63 & $0.32^{*}$ & & 43 & $0.51^{*}$ & & 23 & $0.42^{*}$ & & 3 \\
\hline$*_{0.41}$ & & 64 & $* 0.54$ & & 44 & $0.67^{*}$ & & 24 & $0.44^{*}$ & & 4 \\
\hline${ }^{*} 0.47$ & & 65 & ${ }^{*} 0.42$ & & 45 & $0.42^{*}$ & & 25 & $0.79^{*}$ & & 5 \\
\hline$*_{0} 0.37$ & & 66 & $* 0.74$ & & 46 & $* 0.42$ & & 26 & $0.33^{*}$ & & 6 \\
\hline${ }^{*} 0.30$ & & 67 & $* 0.54$ & & 47 & $* 0.26$ & & 27 & $0.78^{*}$ & & 7 \\
\hline $0.67^{*}$ & & 68 & $* 0.74$ & & 48 & $*^{*} 0.26$ & & 28 & $0.80^{*}$ & & 8 \\
\hline $0.32^{*}$ & & 69 & ${ }^{*} 0.50$ & & 49 & $*_{0.46}$ & & 29 & $0.79^{*}$ & & 9 \\
\hline $0.52^{*}$ & & 70 & $*_{0.72}$ & & 50 & ${ }^{*} 0.60$ & & 30 & $0.45^{*}$ & & 10 \\
\hline & & & ${ }^{*} 0.70$ & \multirow{8}{*}{ 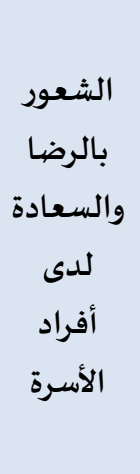 } & 51 & ${ }^{*} 0.40$ & \multirow{10}{*}{ للألأسرة الأداء } & 31 & $0.39^{*}$ & \multirow{10}{*}{ الأستقري } & 11 \\
\hline & & & $* 0.73$ & & 52 & $* 0.62$ & & 32 & $0.44^{*}$ & & 12 \\
\hline & & & ${ }^{*} 0.54$ & & 53 & $*^{*} 0.66$ & & 33 & $0.19^{*}$ & & 13 \\
\hline & & & ${ }^{*} 0.49$ & & 54 & $* 0.47$ & & 34 & $0.49^{*}$ & & 14 \\
\hline & & & $*_{0}^{*} .22$ & & 55 & $* 0.41$ & & 35 & $0.34^{*}$ & & 15 \\
\hline & & & ${ }^{*} 0.66$ & & 56 & ${ }^{*} 0.47$ & & 36 & $0.51^{*}$ & & 16 \\
\hline & & & ${ }^{*} 0.64$ & & 57 & ${ }^{*} 0.37$ & & 37 & $0.24^{*}$ & & 17 \\
\hline & & & $*_{0} 0.69$ & & 58 & $* 0.30$ & & 38 & $0.34^{*}$ & & 18 \\
\hline & & & ${ }^{*} 0.55$ & & 59 & $0.67^{*}$ & & 39 & $0.58^{*}$ & & 19 \\
\hline & & & $*_{0} 0.34$ & & 60 & $0.32^{*}$ & & 40 & $0.33^{*}$ & & 20 \\
\hline
\end{tabular}

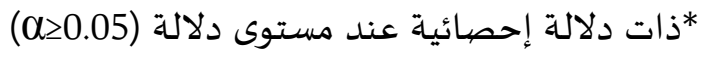


يُظهر الجدول (4) أن جميع معاملات الارتباط بين كل فقرة من فقرات المقياس مع البعد الذي تندرج تحته

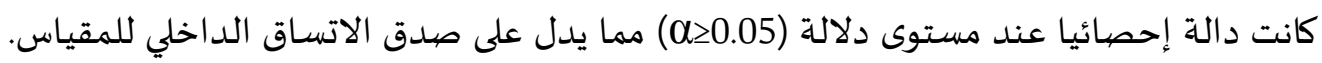

$$
\text { ثبات مقياس الأمن الأسري }
$$

للتحقق من ثبات مقياس الأمن الأسري تم تطبيق المقياس على (30) من الآباء من مجتمع الدراساة ومن

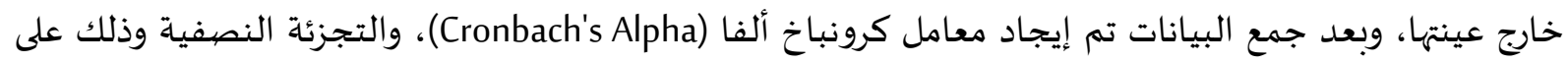
مستوى كل بعد من ابعاد المقياس والجدول رقمى (5) يوضيح ذلك. جدول رقم (5): معاملات ثبات مقياس الأمن الأسري

\begin{tabular}{|c|c|c|}
\hline التجزئة النصيفية & كرونباخ الفا & 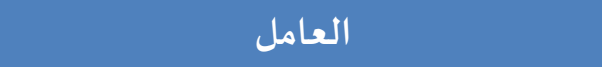 \\
\hline 0.76 & 0.81 & قدرة الأسرة على حل المشكلات \\
\hline 0.41 & 0.40 & الاستقرار الأسـري \\
\hline 0.59 & 0.68 & التماسك الأسري \\
\hline 0.73 & 0.59 & الأداء الوظيفي للأسرة \\
\hline 0.80 & 0.80 & العلاقات الأسرية \\
\hline 0.78 & 0.79 & الشعور بالرضا والسعادة لدى أفراد الأسرة \\
\hline 0.66 & 0.66 & تجنب الصراعات الأسرية \\
\hline
\end{tabular}

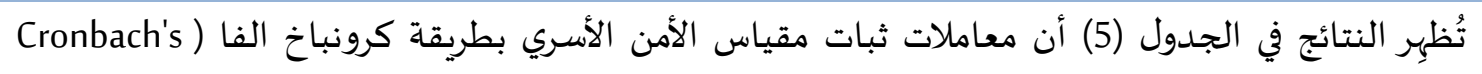

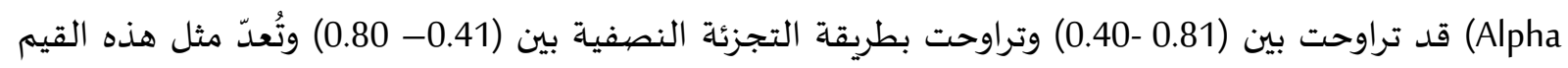
مقبولة لأغراض الدراسـة الحالية.

$$
\text { إجراءات الدراسـة }
$$

تم الحصول على موافقة الآباء المشتركين في الدراسة في منطقة الكرك الأردنية بهدف جمع بيانات الدراسة

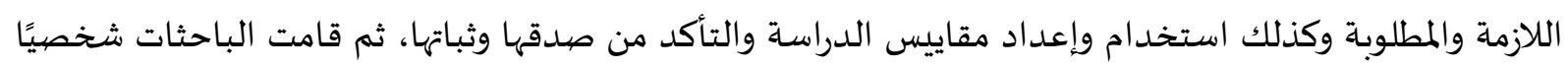
وبالتعاون بتوزيع المقاييس على عينة الدراسة ثم تفريغ الإجابات ومعالجتها إحصائياً.

$$
\text { متغيرات الدراسة: }
$$

المعالجة الإحصائية المستخدمة

تم إيجاد المتوسطات الحسابية والانحرافات المعيارية لأفراد العينة على (مقياس عوامل الشخصية، والميل

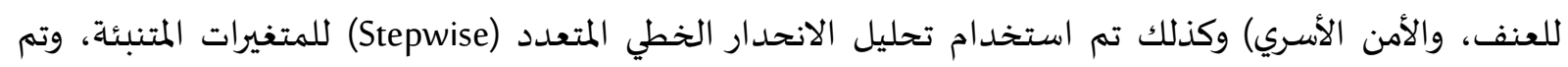

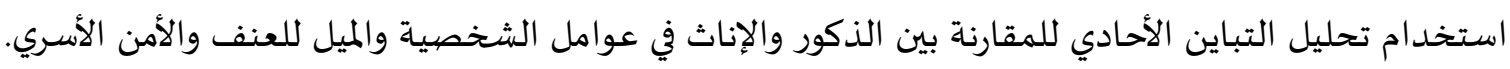


السؤال الأول والذي ينص على: ما عوامل الشخصية الأبرز لدى الآباء؟

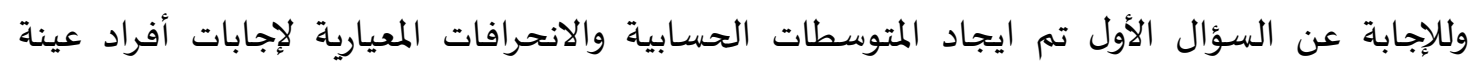

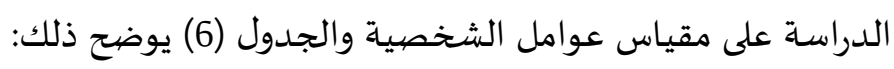
جدول (6): المتوسطات الحسابية والانحرافات المعيارية لاستجابات أفراد عينة الدراسة على على مقياس عواس عوامل الشخصية

\begin{tabular}{|c|c|c|c|}
\hline المستوى & الانحراف المعياري & الوسط الحسـابي & عوامل الشخصية \\
\hline متوسط & 0.44 & 3.27 & العصابية \\
\hline متوسط & 0.58 & 3.06 & الانفتاح على الخبرة \\
\hline متوسط & 0.57 & 2.95 & يقظة الضمير \\
\hline متوسط & 0.62 & 2.92 & الانبساطية \\
\hline متوسط & 0.70 & 2.83 & المقبولية \\
\hline
\end{tabular}

يتضح من الجدول (6) أن أكثر عوامل الشخصية انتشاراً بين الآباء هو عامل العصابية وبمتوسط حسابي

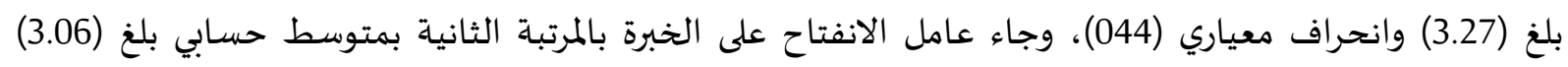

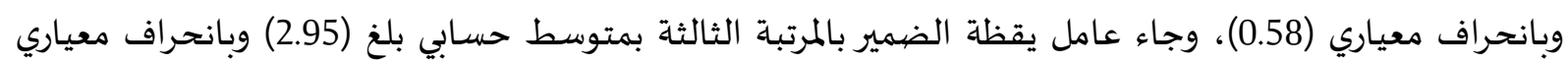
(0.57) وجاء بالمرتبة الرابعة عامل الانبساطية بمتوسط حسابي بلغ (2.92) وبانحراف معاء معياري (0.62)، وأخيرًا بالمرتبة

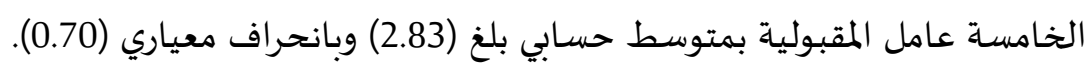

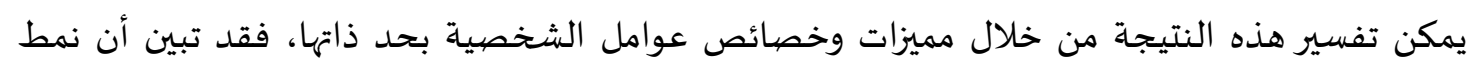

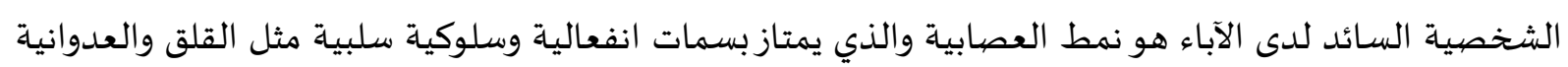

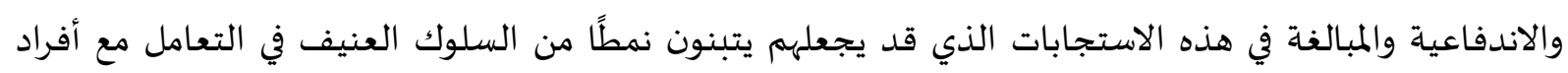

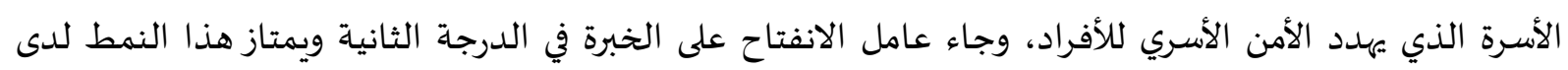

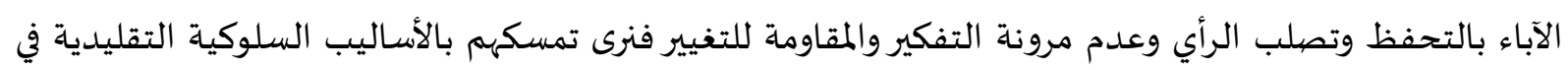

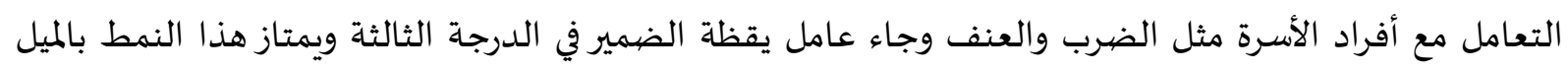

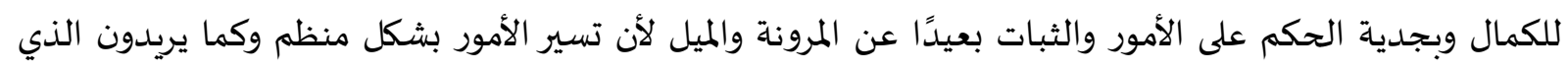

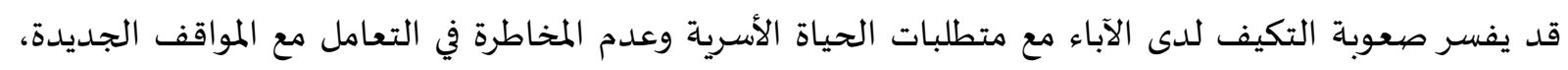

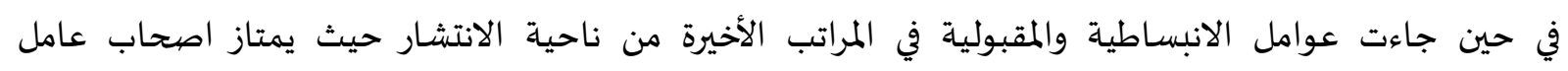

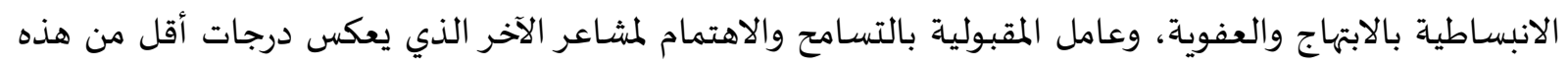
السلوكيات لدى الآباء في التعامل مع أفراد الأسرة. وتتفق هذه النتيجة مع دراسة (Motevaliyan, et al, 2017) التي اشارت نتائجها أن عامل العصابية يلعب العباد

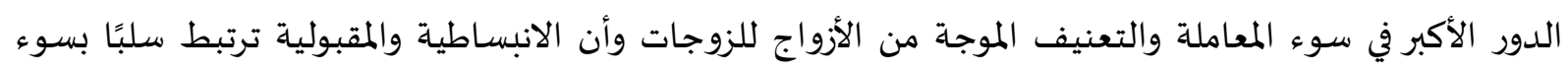

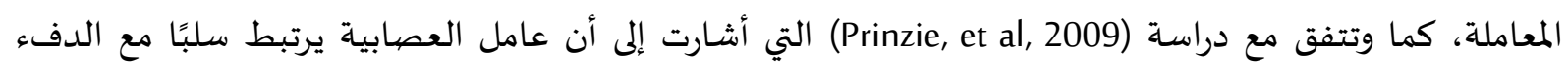
الأسري والتحكم السلوكي التي تعد إحدى مؤشرات الأمن الأسري.

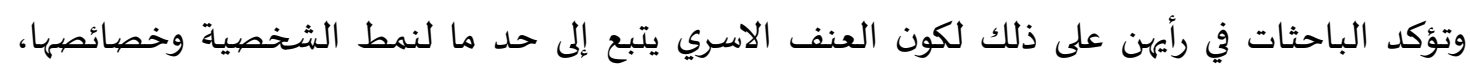

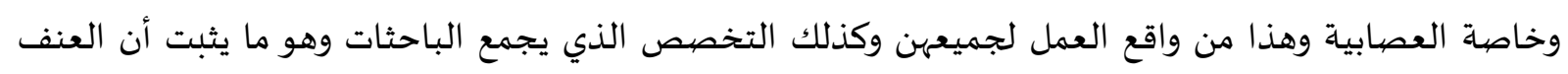


تحديدا يرافق نمط العصابية والانفتاح الحضاري والفكري الزائد، فهناك ما يشير لدى حماية الاسرة الاردنية في

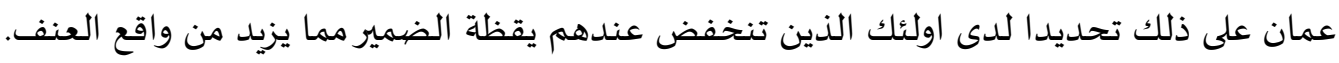

السؤال الثاني: ما مقدار ما تتنباً به عوامل الشخصية بالميل للعنف لدى الآباء؟ ولإجابة عن هذا السؤال تم اجراء تحليل الانحدار الخطي المتعدد (Stepwise) للقدرة التنبؤية لعوامل

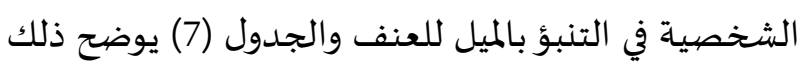
جدول (7): نتائج تحليل الانحدار الخطي المتعدد للقدرة التنبؤية لعوامل الشخصية بالميل لـوليل للعنف

\begin{tabular}{|c|c|c|c|c|c|}
\hline مستوى الدلالة & قيمة T T & المتفير الى التباين ماينيف & نسبة التباين & 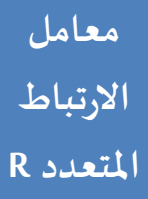 & المتغيرات المتنبئة \\
\hline $0.000^{*}$ & 49.57 & 0.172 & 0.172 & 0.414 & العصابية \\
\hline $0.000 *$ & 11.60 & 0.095 & 0.267 & 0.517 & يقظة الضمير \\
\hline
\end{tabular}

ذات دلالة إحصائية على مستوى(1)

يتضح من الجدول رقم (7) أن هناك عاملين من عوامل الشخصية وهي (العصابية، ويقظة الضيمير) دلت

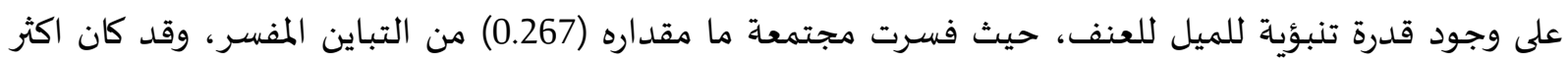

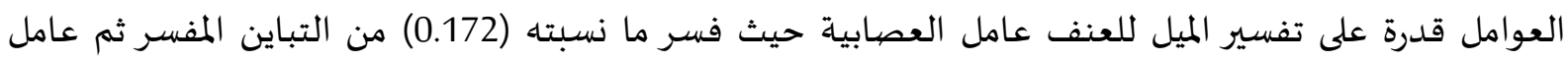
يقظة الضمير وفسر ما نسبته (0.095) من التباين ويمكن تفسير هذه النتيجة من خلال مميزات وخصائص عوامل

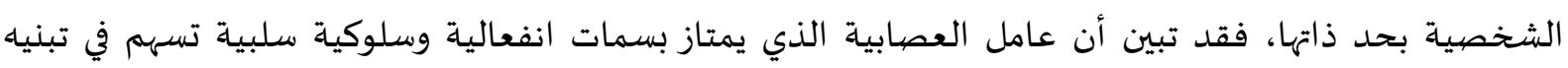

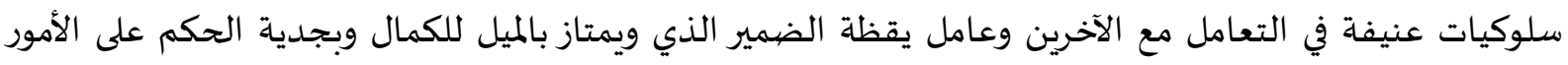

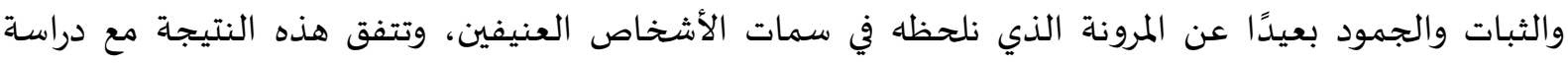

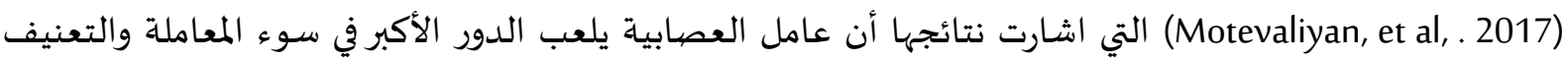

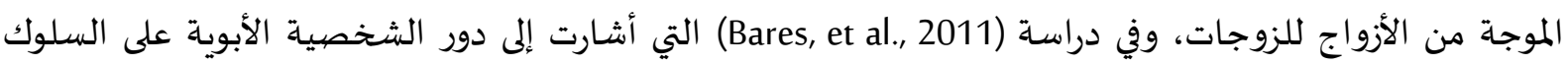
العنيف للمراهقين داخل الأسر.

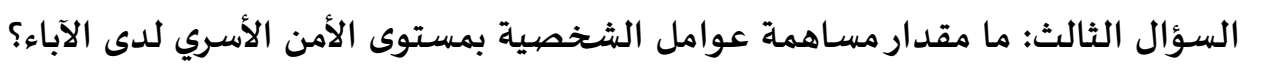

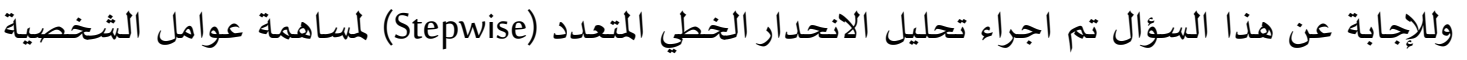

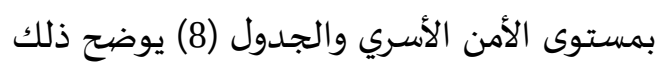

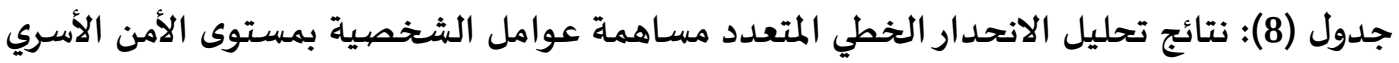

\begin{tabular}{|c|c|c|c|c|c|}
\hline مستوى الدلالة & قيمة T & المتفير المى التباين ماينه & نسبة التباين & $\begin{array}{c}\text { الارتباط معامل } \\
\text { R المتعدد }\end{array}$ & المتخيرات المتنبئة \\
\hline $0.000^{*}$ & 21.60 & 0.132 & 0.132 & 0.363 & الانفتاحية \\
\hline $0.000^{*}$ & 15.50 & 0.057 & 0.189 & 0.435 & يقظة الضمير \\
\hline
\end{tabular}

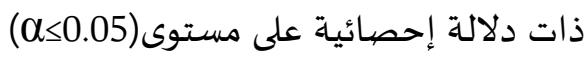


يتضح من الجدول رقم (8) أن هناك عاملين من عوامل الشخصية وهي (الانفتاحية، يقظة الضمير) دلت

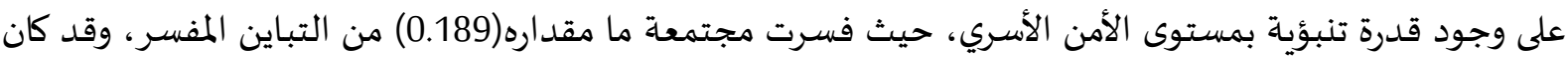

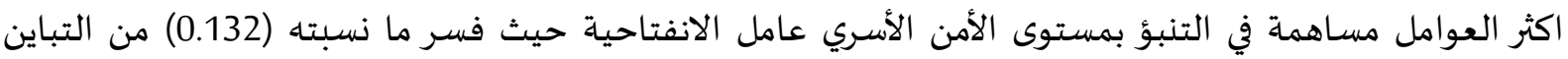

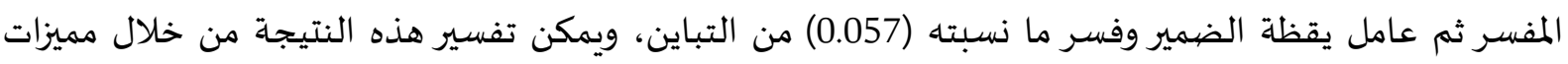

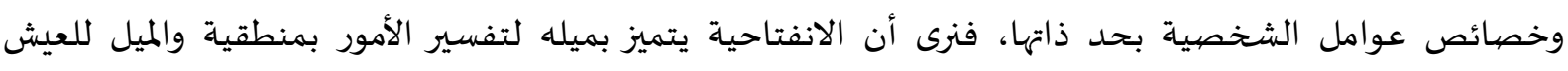

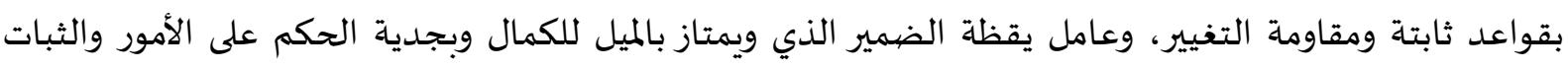

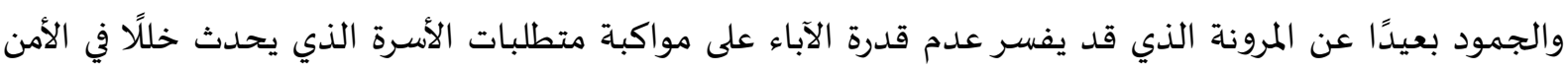
الأسري.

وتفق هذه النتيجة مع دراسـة (Prinzie, et al, . 2009) والتي أشارت أن عامل الانفتاح على الخبرة ويقظة

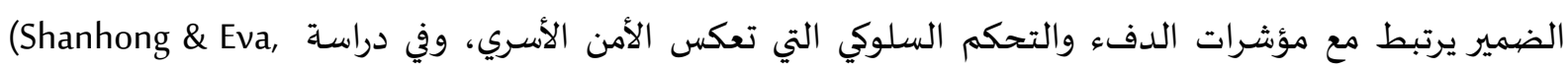
(2005 التي أشارت أن عامل الانفتاح على الخبرة يعكس مستويات الدف والتحكي متدنية من التوافق الزوابي.

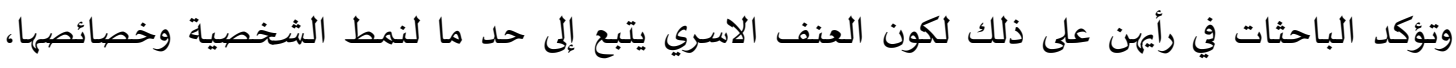

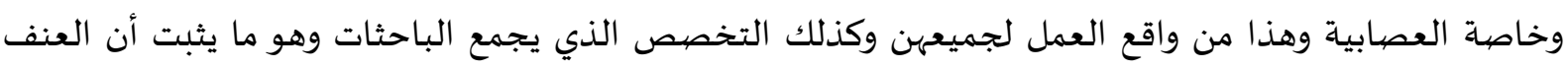

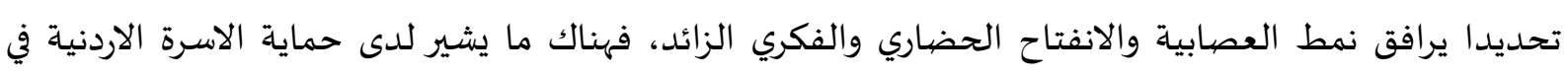
عمان على ذلك تحديدا لدى اولئك الذين تنخفض عندهم يقظة الضيمير الفضئ مما يزيد من واقع العنف.

السؤال الرابع: هل توجد علاقة دالة إحصائياً عند مستوى (O<0.05) بين عوامل الشخصية والميل للعنف

لدى الآباء؟

وللإجابة عن السؤال تم استخراج معاملات ارتباط (Pearson correlation) بين عوامل الشخصية والميل

$$
\text { للعنف لدى الآباء والجدول (9) يوضح ذلك ابلك }
$$

الجدول (9) معاملات ارتباط(Pearson correlation) يين عوامل الشخصية والميل للعنف (العدد= 422)

\begin{tabular}{|c|c|c|c|c|}
\hline العنف اللفظي & العنف البلدي & العنف التنفيذي & الارتباط & المتغير \\
\hline-.077 & $.345(* *)$ & .035 & Pearson correlation & \multirow{2}{*}{ العصيابية } \\
\hline .588 & .007 & .798 & Sig.(2-tailed) & \\
\hline-.068 & -.096 & -.057 & Pearson correlation & \multirow{2}{*}{ الانفتاح على الخبرة } \\
\hline .614 & .0476 & .0673 & Sig.(2-tailed) & \\
\hline .041 & -.131 & .093 & Pearson correlation & \multirow{2}{*}{ يقظة الضمير } \\
\hline .760 & .333 & 0493 & Sig.(2-tailed) & \\
\hline .134 & -.020 & -.016 & Pearson correlation & \multirow{2}{*}{ الانبسـاطية } \\
\hline .321 & .880 & .904 & Sig.(2-tailed) & \\
\hline-.068 & -.096 & -.057 & Pearson correlation & \multirow{2}{*}{ المقبولية } \\
\hline .614 & .476 & .673 & Sig.(2-tailed) & \\
\hline
\end{tabular}

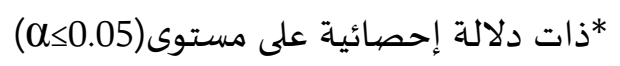

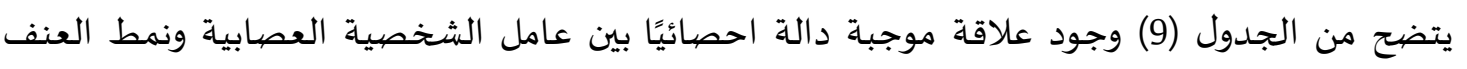

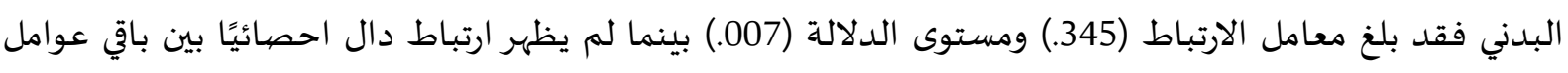

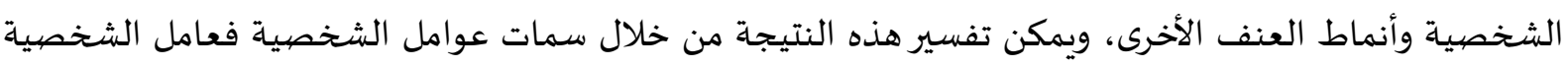


العصابية والذي يمتاز بسمات انفعالية وسلوكية سلبية مثل القلق والعدوانية والاندفاعية والمبالغة في هذه

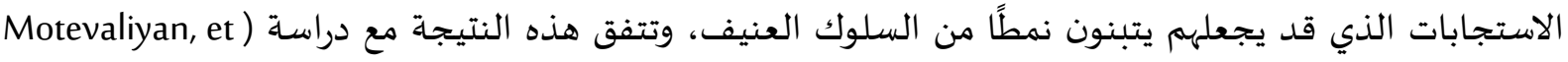

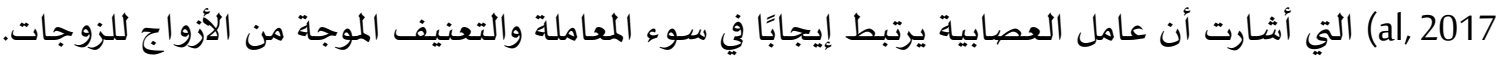

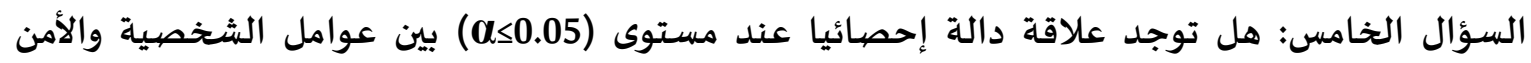
الأسري لدى الآباء؟

وللإجابة عن السؤال تم استخراج معاملات ارتباط (Pearson correlation) بين عوامل الشخصية والأمن

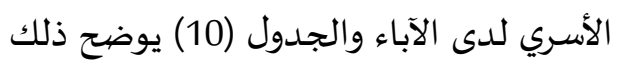

الجدول (10) معاملات ارتباط (Pearson correlation) بين عوامل الشخصية والأمن الأسري (العدد= 422)

\begin{tabular}{|c|c|c|c|c|c|c|c|c|}
\hline الهبراعات & بالرضيا الشعور & العلاقات الأسرية & الوظيفي الأداء & الأسماسك & الأستقرار & حل المثدرة على & الارتباط & المتغير \\
\hline-0.068 & 0.199 & $-0.258(*)$ & $0.482(*)$ & 0.011 & $-0.214(*)$ & $-0.264(*)$ & Pearson correlation & \multirow{2}{*}{ العصيابية } \\
\hline 0.614 & 0.137 & 0.000 & 0.000 & 0.341 & 0.008 & 0.015 & Sig.(2-tailed) & \\
\hline 0.014 & 0.087 & 0.044 & $0.233(*)$ & 0.107 & 0.019 & -0.071 & Pearson correlation & \multirow{2}{*}{ على الانفتاح } \\
\hline 0.916 & 0.518 & 0.507 & 0.031 & 0.194 & 0.686 & 0.542 & Sig.(2- tailed) & \\
\hline 0.077 & 0.125 & $-0.433\left(^{*}\right)$ & 0.042 & $0.210\left(^{*}\right)$ & $0.206\left(^{*}\right)$ & 0.131 & Pearson correlation & \multirow{2}{*}{ الضيمير } \\
\hline 0.567 & 0.353 & 0.033 & 0.506 & 0.038 & 0.016 & 0.065 & Sig.(2-tailed) & \\
\hline-0.049 & 0.203 & 0.077 & -0.089 & $0.212\left(^{*}\right)$ & 0.131 & 0.105 & Pearson correlation & \multirow{2}{*}{ الانبساطية } \\
\hline 0.716 & 0.129 & 0.237 & 0.122 & 0.040 & 0.066 & 0.192 & Sig.(2-tailed) & \\
\hline 0.069 & 0.097 & -0.089 & 0.038 & 0.011 & -0.062 & -.020 & Pearson correlation & \multirow{2}{*}{ المقبولية } \\
\hline 0.608 & 0.474 & 0.967 & 0.245 & 0.224 & 0.112 & .0151 & Sig.(2- tailed) & \\
\hline
\end{tabular}

ذات دلالة إحصائية على مستوى(2-0.05) (1)

يشير الجدول (10) إلى وجود علاقة سالبة ذات دلالة احصائية بين عامل العصابية والقدرة على حل ملإلى

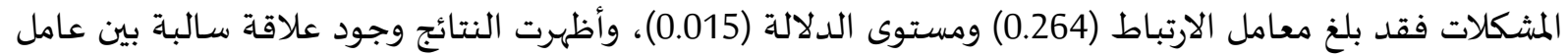
العصابية والاستقرار الأسري فقد بلغ معامل الارتباط (0.214) ومستوى الدلالة (0.008)، كما وأظهر وجود علاقاقة ذات دلالة احصائية بين عامل العصابية والأداء الوظيفي الأسرية بمعامل ارتباط (0.482) ومستوى دلالة (0.000) وعلاقة سالبة ذات دلالة احصائية مع العلاقات الأسرية بمعامل ارتباط (0.258) ومستوى دلالة (0.000)، ، وأشارت الاته

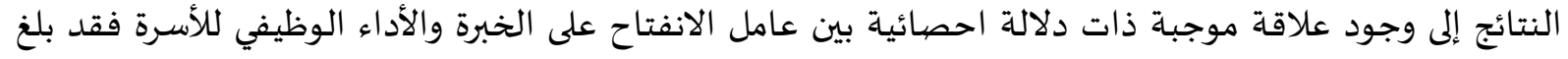
معامل الارتباط (0.233) ومستوى دلالة (0.031)، كما وأظهرت النتائج وجود علاقة موجبة ذات دلالة احصائية بين

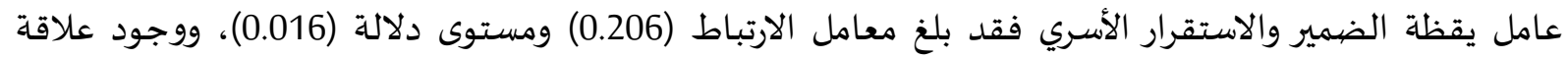

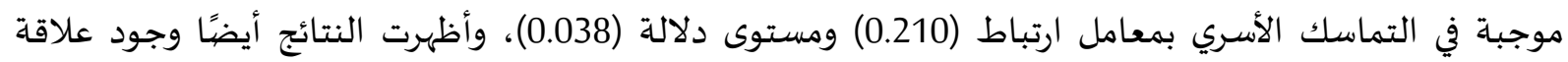
سالبة بين عامل يقظة الضمير والعلاقات الأسرية بمعامل ارتباط (0.433) ومستوى دلالة (0.033)، وأخيرًا أشارت النتائج إلى وجود علاقة ذات دلالة احصائية بين عامل الانبساطية والتماسك الأسري بمعامل ارتباط لماط (0.212)

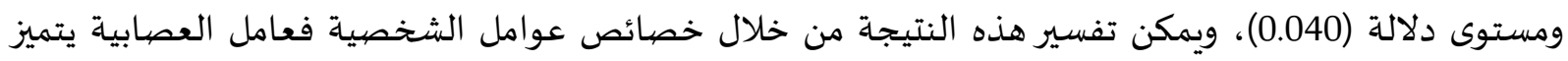

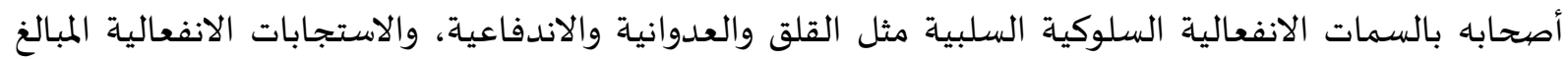
فيها، وصعوبة العودة للحالة الطبيعية التي كانوا عليها قبل مرورهم بالخبرة الانفعالية، وعدم الاستقرار الانفعالي،

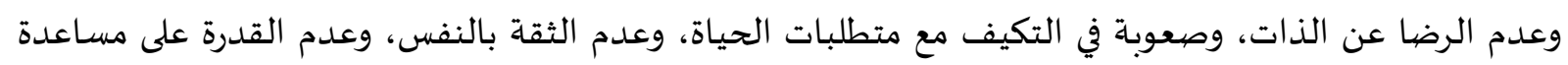


الآخرين الذي قد ينعكس على قدراتهم في حل المشكلات وقدرتهم في الحفاظ على مستوى مناسب من الاستقرار

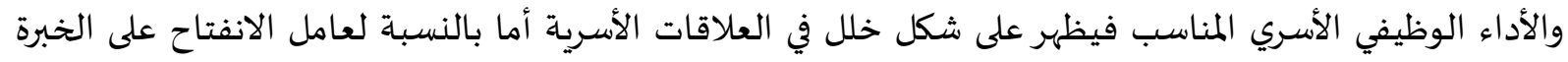

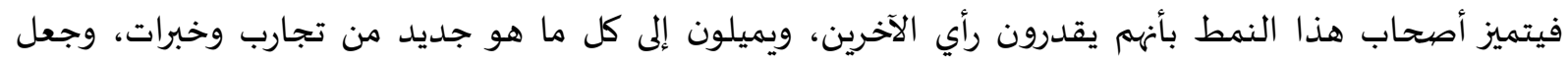

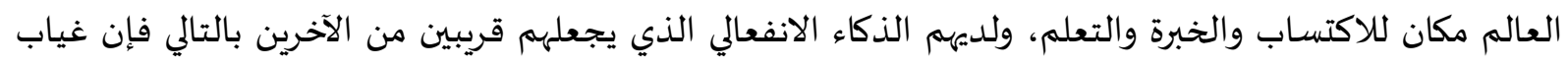

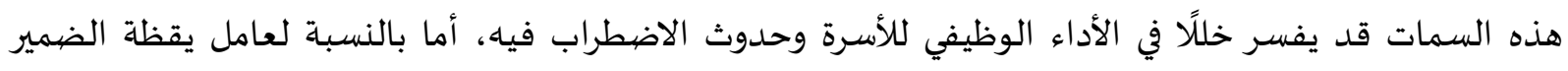

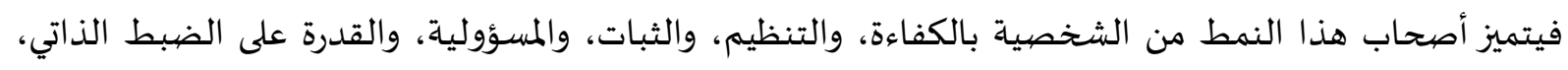
والتفكير والتأني قبل القيام بأي سلوك، والتصرف مدئ بحكمة والالتزام بالواجبات والمسؤوليات بناءً على ما يمليه عليه

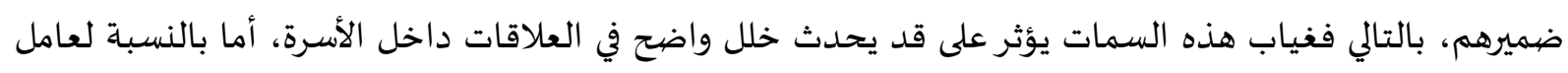

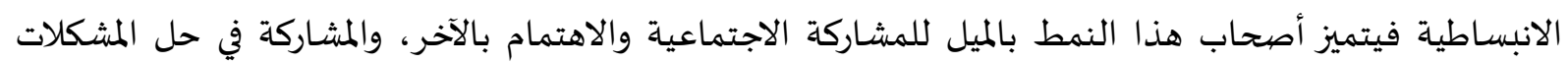

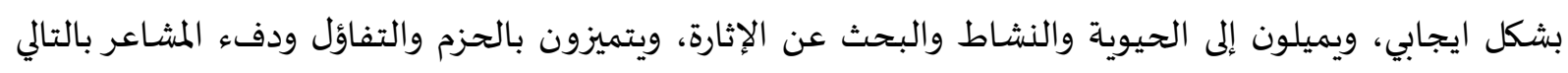

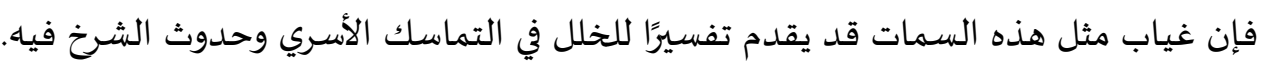

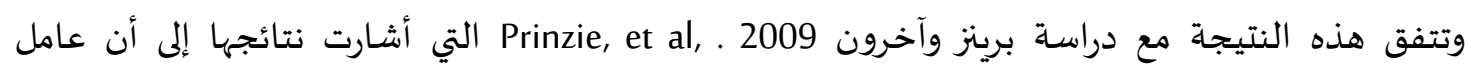

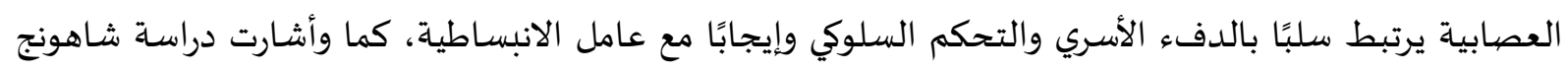

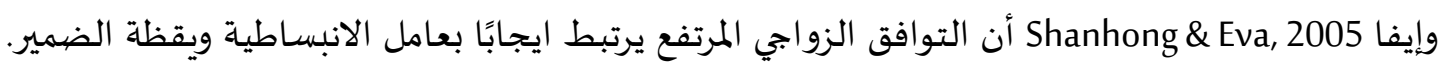

\section{التوصيات والمقترحات}

من خلال نتائج الدراسة توصي الباحثات ويقترحن ما يلي:

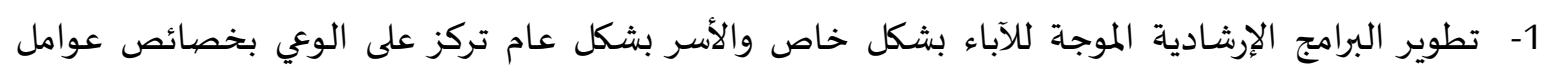

$$
\text { الشخصية وأثرها على استقرار الأسرة. }
$$

2- عقد ورشات عمل وتنظيم حملات توعية للمجتمعات العربية عامة والأردني بشكل خاص والتعريف بأثر

$$
\text { العنف وتهديده للأمن الأسري واستقراره. }
$$

3- تقديم ورشات عمل تستهدف الأخصائيين النفسيين تسهم في رفع الامكانات لديهم في التعامل وإدارة العنف

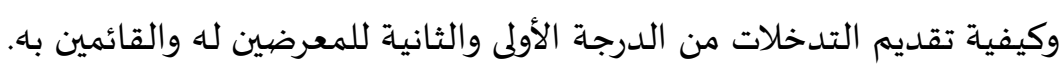

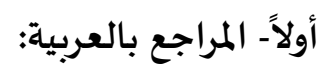
- - ابريعيم، سامية (2011). أساليب معاملة الأب كما يدركها الأبناء وعلاقتها بالشعور بالأمن النفسي لدى عينة من طلاب المرحلة الثانوية في مدينة تبسة، مجلة جامعة النجاح للأبحاث، 2011).

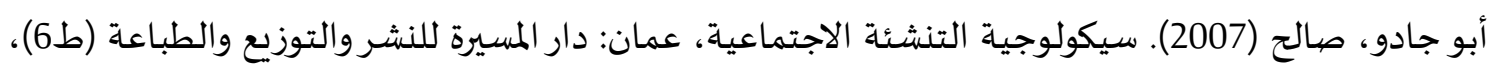

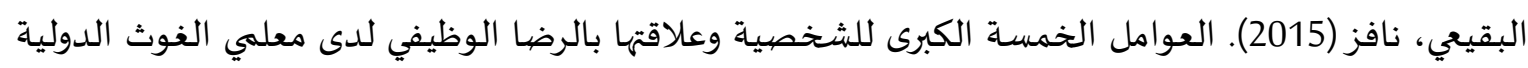

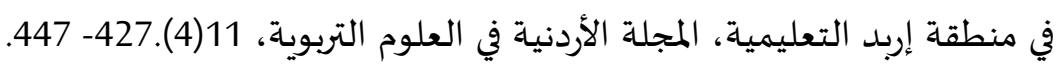
تقرير المجلس الوطني لشؤون الأسرة، 2017.

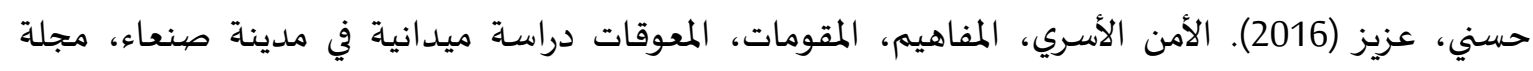
الأندلس، 12(15).161- 231. - الربيع، محمد (2007). قياس الشخصية، عمان: دار المسيرة للنشر والتوزيع، (ط1). 
- الزعبي، نزار (2009). العوامل الخمسة الكبرى للشخصية وعلاقتها بالذكاء الانفعالي ومركز الضبط وكشف الذات لدى عينة من طلبة كلية التربية بجامعة اليرموك في ضوء بعض المتغيرات، رسالة دكتوراه غير منشورة،

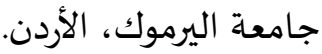

السميري، نجاح (2010). المساندة الاجتماعية وعلاقتها بالأمن النفسي لدى أهالي البيوت المدمرة خلال العدوان

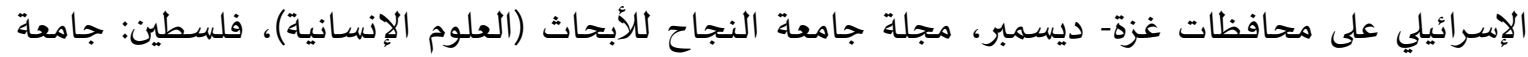

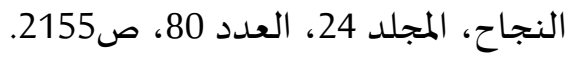

السويطي، عبد الناصر (2012). العنف الأسري الموجه نحو الأبناء وعلاقته بالشعور بالأمن لدى عينة من طلبة النداء الصف التاسع في مدينة الخليل، مجلة جامعة الأزهر، 14(1).281- 310. الطيار، فهد (2013). العلاقة التفاعلية في التنشئة الاجتماعية بين الآباء والأبناء وعلاقتها بالأمن الأسري: دراسة الأسة

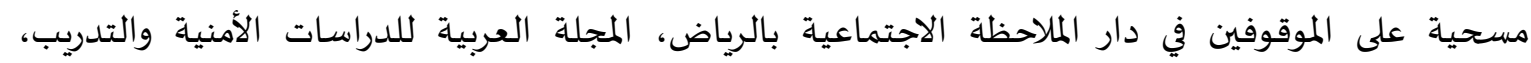
$.437-405 .(58) 29$ علي، ربان؛ ويوسف، هاجر (2017). الضغوط النفسية وعلاقتها بالأمن النفسي لدى الازواج الذين يعانون من

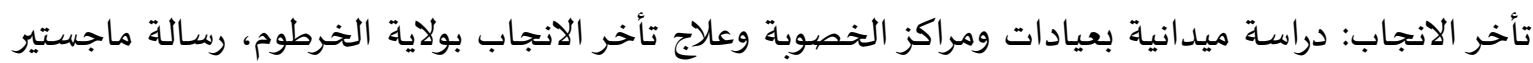
غير منشورة، جامعة افريقيا العالمياة، السودان. الفراية، عمر (2006). العنف الأسري الموجة نحو الأبناء وعلاقته بالأمن النفسي، رسالة ماجستير غير منشورة، جامعة مؤتة، الأردن.

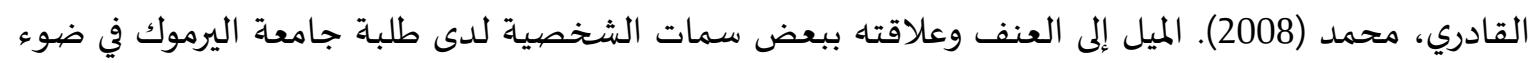
بعض المتغيرات، رسالة دكتوراه غير منشورة، جامعة اليرموك، الأردن.

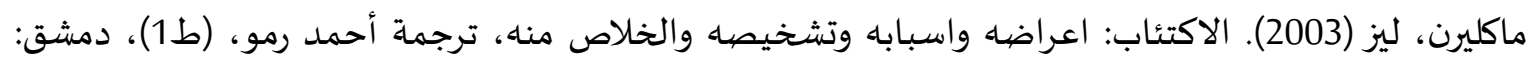
دار علاء الدين للنشر والتوزيع والترجمة. مانزي، كوام (2004). الاكتئاب، ترجمة جولي صليبا، (ط1)، لبناء واءنان: أكاديميا لبنان.

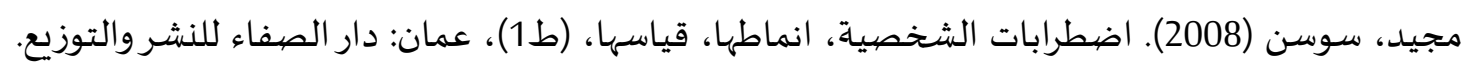

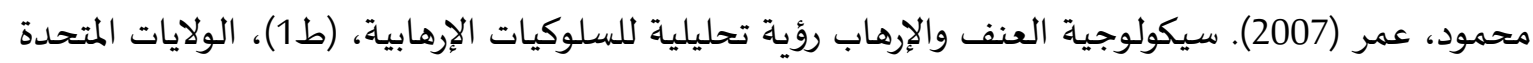
الأمريكية: أكاديمية ميتشجودان للدراسات النفسية. منظمة الصحة العالمية (2015). دليل العنف القائم على النوع الاجتماعي.

\section{ثانياً- المراجع بالإنجليزية:}

- Abigail, J., Graham, N., Archer, J(2010) Adaptive and Maladaptive personality Traits Predictors of Violent and Nonviolent Offending Behavior in Men and Women, . Aggressive Behavior, 35(2).1- 10.

- Asendorpf, B \& Van, M, (2003) Validity of big five personality judgments in childhood, European Journal of personality, 17(1), 1- 17.

- Cohn, D., Cowan, C., Cown, P. \& Person, J (1992) Mothers and fathers working models of childhood attachment relationships, parenting styles and child behavior, Development and Psychology, (4), 414418. 
- Corey, Gerald (2009) Theory and practice of Counseling and Psychotherapy, (8th Ed), Belmont: Thomson Brooks.

- Costa, P. \& MaCrae, R, Odessa, FL (1992) Revised (NEO) Personality Inventory (NEOPI- R) and NEO Five- Factors Inventory (NEO- FFI) Professional Manual: Psychological Assessment Resources.

- Davies, P \& Forman, E, (2002) Children is Patterns of Presenting Emotional Security in the Interparental SubsystemJournal of Child Development.73(6).1880-1903.

- Ghile, Bares, C., Delva, J., Grogan, A., Andrade, F (2011) Personality and Parenting Processes Associated with Problem Behaviors: A Study of Adolescents in Santiago, Social Work Research, 35(4).227- 240.

- Glaser, D., Prior, V.\& Lynch, M. (2001) Predicting Emotional Child Abuse and Neglect: Antecedent, Operational Definitions and Consequences. NY: BASPCAN.

- John, O., Donahue, E., \& Kentle, R (1991) The Big Five Inventory: Versions 4a and 5b Institute of Personality and Social Research, University of California, Berkeley.

- Martin, K (1997) Attachment style depression and loneliness in adolescent suicide attempters, , Dissertation Abstracts International, 57 (9), 24- 59.

- Matthews, G., Deary, I. \& Whiteman, M (2003) Personality Traits, (2ed), UK: Cambridge University press.

- Motevaliyan, S., Rumaya, J., Yaacob, S., Mansor, M (2017) Personality Traits and Severity of Wife Abuse among Iranian Women, Asian Social Sciences, 10(7).234- 241.

- Prinzie, P, Maja, D, Reijntjes, A, Stams, G, . Belsky, I (2009) The Relations Between Parents, Big Five Personality Factors and Parenting: A Meta- Analytic Review, Journal of Personality and Social Psychology.97(2).351- 362.

- Rosellini, A., \& Brown, T (2011) The neo Five Factor Inventory Latent Structure Relationship with Dimensions if Anxiety and Depressive Disorders in Large Clinical Sample Assessment, 18(1).27- 38.

- Shonhong, L \& Eva, K (2005) Assortative Mating and Marital Quality in Newlyweds, A coupleCentered Approach, Journal of Personality and Social Psychology.88(2). 304- 325. 